\title{
Quantification of chemical and physical processes influencing ozone during long-range transport using a trajectory ensemble
}

\author{
M. Cain ${ }^{1}$, J. Methven ${ }^{2}$, and E. J. Highwood ${ }^{2}$ \\ ${ }^{1}$ Centre for Atmospheric Science, Department of Chemistry, University of Cambridge, UK \\ ${ }^{2}$ Department of Meteorology, University of Reading, UK \\ Correspondence to: M. Cain (michelle.cain@atm.ch.cam.ac.uk) \\ Received: 28 September 2011 - Published in Atmos. Chem. Phys. Discuss.: 27 January 2012 \\ Revised: 29 June 2012 - Accepted: 12 July 2012 - Published: 3 August 2012
}

\begin{abstract}
During long-range transport, many distinct processes - including photochemistry, deposition, emissions and mixing - contribute to the transformation of air mass composition. Partitioning the effects of different processes can be useful when considering the sensitivity of chemical transformation to, for example, a changing environment or anthropogenic influence. However, transformation is not observed directly, since mixing ratios are measured, and models must be used to relate changes to processes. Here, four cases from the ITCT-Lagrangian 2004 experiment are studied. In each case, aircraft intercepted a distinct air mass several times during transport over the North Atlantic, providing a unique dataset and quantifying the net changes in composition from all processes. A new framework is presented to deconstruct the change in $\mathrm{O}_{3}$ mixing ratio $\left(\Delta \mathrm{O}_{3}\right)$ into its component processes, which were not measured directly, taking into account the uncertainty in measurements, initial air mass variability and its time evolution.

The results show that the net chemical processing $\left(\Delta \mathrm{O}_{3 \text { chem }}\right)$ over the whole simulation is greater than net physical processing $\left(\Delta \mathrm{O}_{3 \text { phys }}\right)$ in all cases. This is in part explained by cancellation effects associated with mixing. In contrast, each case is in a regime of either net photochemical destruction (lower tropospheric transport) or production (an upper tropospheric biomass burning case). However, physical processes influence $\mathrm{O}_{3}$ indirectly through addition or removal of precursor gases, so that changes to physical parameters in a model can have a larger effect on $\Delta \mathrm{O}_{3 \text { chem }}$ than $\Delta \mathrm{O}_{3 \text { phys }}$. Despite its smaller magnitude, the physical processing distinguishes the lower tropospheric export cases, since the net photochemical $\mathrm{O}_{3}$ change is $-5 \mathrm{ppbv}$ per day in all three cases.
\end{abstract}

Processing is quantified using a Lagrangian photochemical model with a novel method for simulating mixing through an ensemble of trajectories and a background profile that evolves with them. The model is able to simulate the magnitude and variability of the observations (of $\mathrm{O}_{3}, \mathrm{CO}, \mathrm{NO}_{\mathrm{y}}$ and some hydrocarbons) and is consistent with the time-average $\mathrm{OH}$ following air-masses inferred from hydrocarbon measurements alone (by Arnold et al., 2007). Therefore, it is a useful new method to simulate air mass evolution and variability, and its sensitivity to process parameters.

\section{Introduction}

Long-range transport is an important factor for determining the atmospheric distribution of $\mathrm{O}_{3}$ (e.g. Li, 2002; Derwent et al., 2008; Fiore et al., 2009). Anthropogenic and biogenic emissions of $\mathrm{NO}_{\mathrm{x}}\left(=\mathrm{NO}+\mathrm{NO}_{2}\right)$ and volatile organic compounds (VOCs) can give rise to net photochemical production of $\mathrm{O}_{3}$ within or immediately downwind of the source region. However, $\mathrm{O}_{3}$ precursors can also be lifted, for example by frontal systems or convection (e.g. Bethan et al., 1998; Cooper et al., 2002), and can then be transported thousands of kilometres in the mid to upper troposphere in a stable condition due to the colder, drier air. Upon descent, the temperature increases by adiabatic compression, increasing the rate of PAN decomposition into active nitrogen species that can cause net photochemical $\mathrm{O}_{3}$ production (e.g. Wild and Akimoto, 2001).

Anthropogenic emissions can also be transported longrange in the lower free troposphere, even with the increased losses due to mixing, wet and dry deposition and 
photochemistry. For example, Owen et al. (2006) used a particle dispersion model to identify transport of North American $\mathrm{CO}$ emissions to the Azores. Enhancements averaging $20 \mathrm{ppbv}$ (maximum $45 \mathrm{ppbv}$ ) of $\mathrm{CO}$ were found during 16 separate events at the ground station at Mount Pico $(2.2 \mathrm{~km}$ altitude), mostly transported from North America at altitudes below $\sim 3 \mathrm{~km}$ over periods of 4 to 7 days. Owen et al. (2006) suggest that this kind of pollutant transport in the lower free troposphere could affect the lower tropospheric $\mathrm{O}_{3}$ in downwind regions. Following the ICARTT (International Consortium for Atmospheric Research on Transport and Transformation) 2004 field work (see Sect. 2), Neuman et al. (2006) showed that in the absence of precipitation, high levels of $\mathrm{HNO}_{3}$ were transported efficiently over the North Atlantic in low-level anthropogenic plumes that were decoupled from the marine boundary layer. Photolysis and oxidation of the exported $\mathrm{HNO}_{3}$ was sufficient to produce hundreds of pptv of $\mathrm{NO}_{\mathrm{x}}$, which was enough to maintain net photochemical $\mathrm{O}_{3}$ production for several days up to $1000 \mathrm{~km}$ over the ocean.

Fiore et al. (2009) have quantified the impact of changing emissions in continental-scale source regions on surface $\mathrm{O}_{3}$ at the same continental receptor regions, using an ensemble of chemical transport models (CTMs). Intercontinental transport was shown to be important for the annual mean $\mathrm{O}_{3}$ response to changing emissions in the multimodel ensemble. The impact on surface $\mathrm{O}_{3}$ in Europe of reducing non-European emissions by $20 \%$ was approximately half the impact of the same change to domestic emissions. NonEuropean emissions reductions had the most impact in spring and late autumn due to more efficient boundary layer ventilation and transport in the midlatitude free troposphere, and a longer $\mathrm{O}_{3}$ lifetime.

In the free troposphere, the mixing timescale is long (of the order 10 days), and photochemical evolution can be even slower (Arnold et al., 2007). Air masses can retain distinct composition for more than a week as they are transported by the winds, experiencing stretching and folding to fine scales. It is therefore not easy to infer chemical transformations from observations at a fixed point. Fluctuations in composition at fixed locations are dominated by changes in the air mass origin and it is therefore difficult to evaluate the chemical component of a model (Methven et al., 2003). The use of a Lagrangian framework is required to overcome this problem, which was a motivation for the ITCT-Lagrangian 2004 (International Transport and Chemical Transformation) experiment (described in Sect. 2).

Although air masses associated with coherent ensembles of trajectories tend to have distinct composition with marked gradients between the air mass and its surroundings (e.g. Bethan et al., 1998; Methven et al., 2003), inevitably there will also be variability of all species within an air mass. Typically, the variability will be greatest in primary pollutants close to source regions, and decay with time through the combination of mixing and chemistry. In the trajectory ensemble approach used here, composition is initialised from fine-scale data and the composition transforms photochemically while mixing between ensemble members. Thus both the evolution of centroid composition and the variability about it is simulated. This information is crucial in the comparison with data downstream and quantitative evaluation of model performance. In general, the centroid is the geometric centre of a feature - in this case, a polluted air mass. Here, centroid composition is defined as evolution following the trajectory that passes closest to all the downstream matching flight segments in the ITCT-Lagrangian experiment. The specific centroid trajectory is referred to here as the reference trajectory.

The main aim here is to study the different processes acting on air masses in examples of long-range transport, by quantifying the time-integrated effects of different processes affecting chemical composition. The most novel aspect of this study is the combination of a model with fully coupled photochemistry and mixing with measurements that have been shown to be within the same air mass - even though they are separated by up to 10 days, at locations spanning between continents. The Lagrangian model is initialised with observed data from the upwind flight and then transformation during intercontinental transport can be compared with the linked observations downwind. By using a trajectory ensemble, the observed variability within the air mass evolves. This is used to test whether the simulated transformation is consistent with the observations, given the observed variability. It is important to use a model with fully coupled photochemistry and mixing, as the processes are inextricably linked. By partitioning the accumulated changes in $\mathrm{O}_{3}$ mixing ratio $\left(\Delta \mathrm{O}_{3}\right)$ by process along a trajectory, it is possible to investigate how photochemistry, deposition and mixing interact and cause $\mathrm{O}_{3}$ to evolve during transport.

The model used in this work (Cambridge Tropospheric Trajectory model of Chemistry and Transport or CiTTyCAT), including the new ensemble mixing scheme, is described in Sect. 3. The modelled ensembles for each case are compared with the Lagrangian observations of several chemical species in Sect. 4. This is followed in Sect. 5 by a set of experiments to test the sensitivity of modelled $\mathrm{O}_{3}$ to changing the physical parameters of the model. In Sect. 6, the model is evaluated against the Lagrangian measurements of $\mathrm{O}_{3}$ and $\mathrm{CO}$, and the time-averaged $\mathrm{OH}$ inferred from hydrocarbon observations.

The use of a Lagrangian model enables the change in $\mathrm{O}_{3}$ to be partitioned into the component physical and chemical processes, which is explored in Sect. 7. Finally, the conclusions are presented in Sect. 8.

\section{ITCT-Lagrangian 2004 experiment}

In the summer of 2004, an extensive field campaign to study transport and transformation of polluted air masses across the North Atlantic took place, which involved many 
organisations from Europe and North America and was coordinated by ICARTT (Fehsenfeld et al., 2006).

The focus here is on the ITCT-Lagrangian 2004 part of the ICARTT field work. Its aim was to investigate transport of $\mathrm{O}_{3}$ and its precursors, and the processes affecting transformation following the flow, by sampling an air mass several times during its transport across the North Atlantic (Stohl et al., 2004). In experiments that take measurements along a single flight, the uncertainty in modelling the chemical transformation is dominated by uncertainties in the air mass origins (Methven et al., 2003). By intercepting the same air mass several times, these uncertainties are reduced, which was the motivation for the ITCT-Lagrangian 2004 experiment.

Measurements were taken by four research aircraft: two of them being based in Pease, New Hampshire, USA (NASA DC8 and National Oceanic and Atmospheric Administration [NOAA] WP-3D); one at Faial, Azores (Facility for Airborne Atmospheric Measurements [FAAM] BAe146) and one in Creil, France (German Aerospace Centre [DLR] Falcon). The instrumentation and measurements are described by Fehsenfeld et al. (2006). Target plumes were identified for the aircraft based in America to sample using dual criteria that the air should be polluted and forecast to travel in range of the downwind aircraft. Forecast trajectories were then updated daily to predict the plume's onward transport to support the European aircraft flight planning (see Methven et al., 2006, for details). This is the only Lagrangian field experiment, to date, that has taken measurements by targeting polluted air masses close to their sources in North America, and thousands of kilometres downwind over the North Atlantic and Europe, up to ten days later. A special section of the Journal of Geophysical Research (Atmospheres) entitled "International Consortium for Atmospheric Research on Transport and Transformation (ICARTT): North America to Europe" contains papers related to the ICARTT field campaign, including the ITCT-Lagrangian 2004 experiment.

Following the field campaign, Methven et al. (2006) conducted a detailed analysis of the aircraft measurements to identify true Lagrangian matches, where the same air mass was indeed sampled several times. For a pair of observations to be classified as having Lagrangian links, the sampled air masses had to fulfil two criteria: (1) whole air samples from the two intercepts have highly correlated hydrocarbon fingerprints, and (2) the intercepts are linked by trajectories calculated from meteorological analyses. Additionally, the observed thermodynamic tracer, equivalent potential temperature, was used to evaluate the quality of the matches. Methven et al. (2006) identified five distinct cases with Lagrangian links. Cases 1, 2, 3 and 5 from Methven et al. (2006) are investigated here. Case 4 involved ascent in a warm conveyor belt with embedded convection over eastern USA. It is not studied here as the model is not suitable for use in regions with strong convective influence.

\section{Modelling}

\subsection{Modelling approach}

A Lagrangian photochemical model is used to simulate case studies of transport across the North Atlantic. For these cases, a Lagrangian model has three key advantages over a 3-D Eulerian CTM. Firstly, in this framework, it becomes simple to integrate the rates of change in $\mathrm{O}_{3}$ following air masses for physical and chemical processes separately.

Secondly, it is able to retain the integrity of air masses as they thin to finer scales than the grid of a global 3-D model. This is important as the plume chemistry is nonlinear, and so averaging over a larger grid box will give rise to different and possibly erroneous chemistry. For example, two global chemical transport models (the Frontier Research System for Global Change version of the University of California, Irvine CTM and the University of Oslo CTM2) were compared with $\mathrm{O}_{3}$ observations taken during the NASA Transport and Chemical Evolution over the Pacific (TRACE-P) field campaign by Wild et al. (2003). Mean $\mathrm{O}_{3}$ at pressures greater than $800 \mathrm{hPa}$ was $45 \pm 12 \mathrm{ppbv}$ from ozonesonde measurements taken at several locations in the North Pacific, but was overestimated by 5 and $12 \mathrm{ppbv}$ in the models. This overestimation was thought to be caused by the coarse resolution of both models (horizontally $1.875^{\circ} \times 1.875^{\circ}$ and ranging from 500 to $1200 \mathrm{~m}$ in the vertical), through mixing of emissions within model grid boxes. The model with more efficient mixing (FRSGC/UCI) diluted the precursors faster and generated ozone more efficiently than the other (Oslo CTM2). Another issue with this coarse resolution was that the CTMs could not capture the observed small scale structure and layering. Crowther et al. (2002) investigated the effect of unresolved structures on modelled $\mathrm{OH}$, and found that global scale models (horizontal resolutions between $\sim 200$ to $800 \mathrm{~km}$ ) overestimated $\mathrm{OH}$ production by up to 5 to $20 \%$ compared with MOZAIC aircraft data.

Thirdly, since the model is fast to run, many sensitivity studies can be performed. One control simulation and a suite of sensitivity tests are carried out for each case, as described below.

\subsection{Ensemble CiTTyCAT}

The chemical transport model used in this work is the Cambridge Tropospheric Trajectory model of Chemistry and Transport (CiTTyCAT). The model was developed with the aim of reproducing observed synoptic scale variability in species such as $\mathrm{O}_{3}$ and $\mathrm{CO}$ and investigating the factors affecting this evolution (e.g. Wild et al., 1996; Evans et al., 2000; Arnold et al., 2004; Real et al., 2008). Photochemistry and physical processes are integrated along pre-calculated trajectories.

Earlier versions of the CiTTyCAT model parameterised mixing by an exponential decay towards a background 
mixing ratio. Although it is possible to change the mixing timescale and background mixing ratio for different segments along a trajectory (Real et al., 2008), knowledge of the background composition and any changes in meteorology are required to inform this. In addition, in the single trajectory version, a trajectory would only experience dry deposition and emissions whilst it was lower than the boundary layer height. Thus a trajectory that was at the approximate height of the boundary layer could switch back and forth between interacting with the surface and not. It would be preferable for the transition between the boundary layer and free troposphere to be smoother.

Real et al. (2010) tackled these drawbacks by developing a methodology that combined CiTTyCAT with multiple trajectories calculated by Pisso et al. (2009), and a global model for its initialisation, however this method only performed mixing at the end of the simulation (see Sect. 4.2).

Here, the model has been developed to run along an ensemble of trajectories that communicate by mixing in the vertical (see Pugh et al., 2012, for description of the model version used here). The ensemble is used to define an evolving background composition profile. Mixing is assumed to be diffusive in the free troposphere, but also includes a linear flux profile across the boundary layer (characteristic of a boundary layer that is well-mixed in terms of virtual potential temperature). Boundary layer depth at trajectory locations is input from the driving meteorological model. The effects of dry deposition and emissions at the surface are not confined to the boundary layer, as there is exchange across the boundary-layer top. The rates of change in mixing ratio from all chemical and physical processes (including turbulent mixing) both feed into the integration of the coupled rate equations of the model. In this way, full coupling between processes on the shortest timescales is ensured.

Trajectories have been calculated from the ECMWF analysed fields using ROTRAJ (Reading Offline TRAJectory model Methven, 1997). The horizontal resolution of the analyses used in this work is $\mathrm{T} 159\left(\sim 1.125^{\circ}\right)$, and the vertical resolution in hybrid-pressure co-ordinates retains 60 levels (L60). There is a linear interpolation in time and horizontal space, and a cubic interpolation in the vertical, of the meteorological fields (e.g. wind velocity, humidity, temperature) between analysis times, which are every six hours. The location of the trajectory is calculated by integrating the velocity with respect to time using a 4th order Runge-Kutta method (Methven, 1997).

An extended chemistry scheme is used for all the control simulations, and the case 3 sensitivity tests. In the extended scheme, 185 gas-phase species undergo 375 bimolecular, 37 termolecular and 120 photolysis reactions. The extended scheme includes the second edition of the Mainz Isoprene Mechanism (Taraborrelli et al., 2009), implemented as described in Pugh et al. (2010). This is in addition to the basic CiTTyCAT chemistry, which includes the important gas phase reactions of $\mathrm{O}_{\mathrm{x}}, \mathrm{HO}_{\mathrm{x}}, \mathrm{NO}_{\mathrm{x}}$ and methane oxida- tion. The degradation of 9 anthropogenic hydrocarbons from ethene to benzene is also considered (Hough, 1991). In the basic scheme, 90 gas-phase species undergo 177 bimolecular, 41 termolecular and 45 photolysis reactions. All rate constants in these schemes have been updated according to IUPAC (2008) if available, and else according to JPL06-2 (Sander et al., 2006) or MCM 3.1 (Jenkin et al., 1997; Saunders et al., 2003). An isotropic two-stream approach is used to calculate photolysis rates, based on the Harwell model of Hough (1988), with a Chapman function to calculate an effective solar zenith angle for all angles greater than $75^{\circ}$ (Wild, 1995).

The dry deposition velocities are based on Derwent and Jenkin (1991); Jacob et al. (2003); Singh et al. (2003); Karl et al. (2004); Horowitz et al. (2007) and are listed in full (with a full description of how they are handled in the model) by Pugh et al. (2012). A look-up table contains dry deposition velocities for five different surface cover types, using the MEGAN (Model of Emissions of Gases and Aerosols from Nature) plant functional type dataset (Guenther et al., 2006) at a resolution of $0.5^{\circ} \times 0.5^{\circ}$. The dry deposition velocity at a given point depends on the area-weighted surface cover, and has a seasonal and diurnal variation superimposed on the look-up table value.

Wet deposition occurs at a rate proportional to the surface precipitation rate in the ECMWF numerical weather prediction (NWP) model from 6 or $12 \mathrm{~h}$ forecasts produced as part of the forecast-analysis cycle. However, if the trajectory is descending it is assumed to be unsaturated and running above the precipitating clouds so the wet deposition does not affect it.

Anthropogenic emissions are taken from the EDGAR Fast Track 2000 (EDGARFT2000) emissions database (Olivier et al., 2005), which includes emissions of $\mathrm{CH}_{4}, \mathrm{CO}$, $\mathrm{NO}$ and non-methane VOCs on a $1^{\circ} \times 1^{\circ}$ grid, adjusted for the year 2000. The errors associated with this database are $100 \%$ for NM-VOCs and $50 \%$ for the other species. The total lumped non-methane VOCs are split into species based on the European Environment Agency European Core Inventory Air (CORINAIR) emissions (Evans, 1999).

Further details of the model are reported in Pugh et al. (2012).

\subsubsection{Differential equations for evolution of chemical species}

The model calculates the rate of change of the mixing ratio $(c)$ for each chemical species based upon the Lagrangian form of the tracer mass conservation equation:

$$
\frac{D c}{D t}=S-\frac{1}{\rho} \nabla \cdot \mathbf{F},
$$

where $D / D t$ denotes the rate of change following a trajectory, $S$ represents material sources or sinks, $\rho$ is air density and $\mathbf{F}$ is a mass flux representing any transport not 
attributable to advection by the resolved velocity. To define the non-advective fluxes, two assumptions are made. Firstly, that vertical flux divergence dominates, which is a good approximation since vertical gradients are often much greater than horizontal (Haynes and Anglade, 1997). Secondly, it is assumed the vertical component of the non-advective flux $\left(F_{z}\right)$ is composed a linear flux profile across the boundary layer of depth $z_{\mathrm{BL}}$ and a diffusive term acting at all altitudes. In the boundary layer:

$F_{z}=F_{\mathrm{s}}\left(1-z / z_{\mathrm{BL}}\right)+F_{\mathrm{d}}$,

where $F_{\mathrm{S}}$ is the flux at the ground $(z=0)$ and $F_{\mathrm{d}}$ is the diffusive part which obeys a flux-gradient relation:

$F_{\mathrm{d}}=-\rho \kappa \frac{\partial c}{\partial z}$

where $\kappa$ is a diffusion coefficient. Above the boundary layer, $F_{z}=F_{\mathrm{d}}$. A no-flux boundary condition on the diffusion term is used at $z=0$ (as the surface emissions and dry deposition are included in the linear flux profile), and a fixed mixing ratio is the boundary condition at the profile top (at $10 \mathrm{~km}$ ). The definition of the diffusive flux related to the evolving background profile is described in Sect. 3.2.2.

This form of boundary layer parameterisation (Eq. 2) is common practice in numerical weather prediction models. Holtslag (2002) describes boundary layer mixing parameterisations, and includes a form of mixing that modifies the fluxgradient approximation (Eq. 3) to include a non-local term (see Eqs. 14 and 17 in Holtslag (2002), which is the basis for Eq. 2). Diffusion describes turbulent mixing when the eddy scales are much smaller than the length scale of properties being transported. The linear flux profile is a good fit to observations within strongly mixed boundary layers for stable, neutral or unstable conditions. It represents the non-local effects of large eddies mixing across the BL depth. Beljaars (2002) compares a scheme where diffusivity is determined from local stability and the non-local scheme of Troen and Mahrt (1986) in simulations with the ECMWF model; the mixed layer humidity is much closer to observations with the non-local scheme as a result of entrainment of dry air from above the BL and faster mixing within it. In Troen and Mahrt (1986), diffusivity is a prescribed function of $z / z_{\mathrm{BL}}$ with a magnitude scaling with the surface layer buoyancy flux (which is determined from similarity theory) and an additional flux profile term is included. An important part of the scheme "closure" is the calculation of boundary layer depth, $z_{\mathrm{BL}}$. Since CiTTyCAT takes the boundary layer height as input from the ECMWF model, a separate closure scheme is not required.

To bring it all together to form the model equation, it is assumed that in Eq. (1), $\nabla \cdot \mathbf{F}=\partial F_{z} / \partial z$, where the right hand side is the vertical derivative of Eq. (2). The surface fluxes in Eq. (2) are $F_{\mathrm{s}}=\rho E-\rho V_{\text {dry }} c$, where $E$ is the emissions rate from the surface into the boundary layer, and $V_{\mathrm{d}}$ is the dry deposition velocity. The material source in Eq. (1) is the photochemical production $P$. The sinks are from the photochemical loss rate, $L$, and wet deposition rate, $r_{\text {wet }}$, which depend upon $c$.

Combining Eqs. (1), (2) and (3), we obtain the model equation:

$$
\frac{D c}{D t}=P-L c+\left(\frac{E}{z_{\mathrm{BL}}}\right)-\left(\frac{V_{\mathrm{dry}}}{z_{\mathrm{BL}}}+r_{\mathrm{wet}}\right) c-\frac{1}{\rho} \frac{\partial F_{\mathrm{d}}}{\partial z} .
$$

Emissions and dry deposition are only active when the air parcel is inside the boundary layer. The air density $\rho$ falls exponentially from its surface value $\left(\rho_{\mathrm{s}}\right)$ with density scale height $(H=7200 \mathrm{~m})$ according to $\rho=\rho_{\mathrm{s}} e^{-z / H}$, although density and mixing ratio are assumed to be approximately constant across the boundary layer to obtain Eq. (4).

\subsubsection{Vertical mixing using an ensemble}

Since chemistry and mixing are typically non-separable (McKenna, 1997), the model must be run along many trajectories simultaneously, which communicate with each other through the vertical mixing scheme. The ensemble is initialised here using aircraft data at ten second intervals. The model is integrated forwards along the trajectory from the location of each aircraft measurement. Each trajectory evolves by photochemistry, emissions, wet and dry deposition and mixing. However, full diagnostics are not output by the model for every trajectory. Instead, one trajectory is selected to be the focus of the study, for which full diagnostics are saved. Henceforth, this is referred to as the reference trajectory. The reference trajectory lies near the centroid of the trajectory ensemble so that it is always surrounded by others above and below for the purposes of mixing (see Sect. 1 for discussion of the centroid).

The trajectory ensemble that is initialised from aircraft measurements generally does not sample the entire depth of the troposphere. Shadow trajectories are used to simulate the evolution of the background profile above and below the height range of the ensemble. These shadow trajectories follow the horizontal path of the reference trajectory and evolve photochemically, but do not move vertically (see Fig. 8 in Pugh et al. (2012) for an example of shadow trajectories). Their purpose is only to provide suitable far-field concentrations for diffusion of the background profile. An assumption must be made about the initial composition of the shadow trajectories, since they lie beyond the range of the data. Composition is assumed to be constant for shadow trajectories below the lowest altitude data point. Therefore, the lowest altitude observation point is used to initialise all lower shadow trajectories between that point and the surface. Above the aircraft data, the shadow trajectories are initialised by either a uniform value equal to the upper tropospheric boundary condition (case 1), or by a linear interpolation between the highest altitude data point and the boundary condition (cases 2, 3 and 5). In all simulations, the boundary condition at the top of the 
background profile $(10 \mathrm{~km})$ is specified by the average mixing ratios from the "upper troposphere" cluster of ICARTT 2004 aircraft data from Lewis et al. (2007). The rationale for the choices is given in Sect. 4. An alternative way of initialising the shadow trajectories would be to simulate the global background with a global CTM, and to use the results as initial conditions for the shadow trajectories.

Initially, a background profile, $C(z)$, is defined by averaging mixing ratios of trajectories lying within layers of equal depth $(\Delta z)$. Once the background profile is established, the non-advective fluxes $\left(F_{z}\right)$ in each layer are calculated, which will act to evolve both the mixing ratios along each trajectory and the background profile. (See Fig. 7 in Pugh et al. (2012) for a schematic of how the background is defined, and Fig. 9 for examples of background profiles.)

In addition to the turbulent diffusion of the background profile, there is also a sub-grid scale mixing parameterisation, whereby each trajectory mixes with the background concentration in the surrounding layer at a rate derived as follows.

To simplify the argument, consider only diffusion with constant density and diffusivity:

$$
\frac{\partial c}{\partial t}=-\frac{1}{\rho} \frac{\partial F_{\mathrm{d}}}{\partial z}=\kappa \frac{\partial^{2} c}{\partial z^{2}} .
$$

Consider a polluted layer of depth $Z$ containing air of mixing ratio $c$, surrounded above and below by background air of mixing ratios $C_{\mathrm{up}}$ and $C_{\mathrm{down}}$, and approximate the second derivative by a second order finite difference:

$\kappa \frac{\partial^{2} c}{\partial z^{2}} \simeq \kappa \frac{C_{\mathrm{up}}-2 c+C_{\mathrm{down}}}{Z^{2}}=\frac{2 \kappa}{Z^{2}}(C-c)$

where in the last step it was assumed that $C_{\mathrm{up}}=C_{\text {down }}=C$. For the ITCT-Lagrangian cases, Arnold et al. (2007) have inferred a value for the air mass dilution rate in the free troposphere, $K_{\text {mix }}=\frac{2 \kappa}{Z^{2}}$, from measurements of hydrocarbons (see Sect. 6 for a description of their method). The depth $Z$ is found from observations from the aircraft flying a vertical profile. Using these values, $\kappa$ is estimated for each case (see Sect. 4 for details of each case). The model applies a withinlayer relaxation mixing rate in the free troposphere calculated from $\kappa$ and the model level spacing:

$K_{\mathrm{FT}}=\frac{2 \kappa}{\Delta z^{2}}$.

The total mixing tendency acting on a trajectory is the combination of the background vertical flux divergence and the relaxation term:

$$
\frac{D c}{D t}=\frac{1}{\rho} \frac{\partial}{\partial z}\left(\rho \kappa \frac{\partial C}{\partial z}\right)-K_{\mathrm{FT}}(c-C),
$$

where $c$ denotes the mixing ratio of the trajectory and $C$ denotes the background mixing ratio in that layer. This term is referred to in the manuscript as "mixing".
As turbulence in the boundary layer is typically greater than in the free troposphere, the sub-grid relaxation rate there is defined as:

$K_{\mathrm{BL}}=\frac{2 \kappa_{\mathrm{BL}}}{z_{\mathrm{BL}}^{2}}$,

where a larger diffusion coefficient is assumed for the boundary layer than in the free troposphere: $\kappa_{\mathrm{BL}}=10 \kappa$. In the boundary layer, the mixed-layer fluxes also apply (Eq. 2), so the total boundary layer mixing tendency is:

$\frac{D c}{D t}=\frac{1}{\rho} \frac{F_{\mathrm{s}}}{z_{\mathrm{BL}}}+\frac{1}{\rho} \frac{\partial}{\partial z}\left(\rho \kappa \frac{\partial C}{\partial z}\right)-K_{\mathrm{BL}}(c-C)$.

The background profile itself is also evolved using Eqs. (8) and (10) but without the sub-grid terms. Each trajectory evolves its own background profile to be consistent with the surface fluxes it passes over. Since the trajectories within the ensemble do not follow exactly the same horizontal paths, they pass over different emissions and environments (varying surface cover, precipitation, temperature and so on). The background profile is re-defined every "mixing time-step" $(1 \mathrm{~h})$ by layer-averaging across the ensemble. The mixing time-step is chosen so that the background profiles carried on each trajectory do not have time to diverge too far from the ensemble average before being re-defined. In this way, the background profile experiences an ensemble average of emissions, deposition and photochemistry in addition to mixing (which acts on a shorter time-step).

Inevitably, any ensemble of trajectories will spread with time due to wind shear and time-dependent straining. Eventually, it will become a poor approximation to assume that the air neighbouring each trajectory (in the vertical) is described by other trajectories within the ensemble. Each air mass will come into contact with air masses of different origins, far from the initial location of the ensemble. One approach, taken for example by the STOCHEM model of the Met Office, is to fill the atmosphere uniformly with air parcels and calculate their trajectories using winds from a global circulation model, with a sub-grid scale convection parameterisation. Although less computationally expensive, STOCHEM can generate similar tracer patterns to the Met Office's global circulation model (Stevenson et al., 1998), and can give good agreement with observed tropospheric $\mathrm{O}_{3}$ and $\mathrm{NO}_{\mathrm{x}}$ (Collins et al., 1997, 2000). The additional computational cost, however, diminishes an important advantage of using a Lagrangian model in the first place, and the formulation of mixing between parcels is more difficult than in regularly gridded Eulerian models. The simulation time over which a Lagrangian ensemble approach yields accurate solutions will depend upon many factors: the number of ensemble members, initial volume spanned, rate of trajectory spread with time, the rate of mixing and the contrast in composition between the air mass of focus (surrounding the reference trajectory) and all other air masses that it contacts. The utility of 
the approach is evaluated in this paper using Lagrangian observations spanning the breadth of the North Atlantic Ocean.

\section{Ensemble evolution in the ITCT-Lagrangian cases}

The ITCT-Lagrangian observations provide a unique data set for evaluation of photochemical models simulating the evolution of air mass composition. For each case, the observational data are used to initialise composition at the start of trajectories, which leave points along the flight track at $10 \mathrm{~s}$ intervals. The hydrocarbon data from upwind and downwind samples, and observations of the vertical extent of the air mass, are used to estimate diffusion coefficients for the mixing parameterisation as described in Sect. 3.2.2. The trajectories' initial conditions and mixing parameters therefore depend on the meteorological analyses and available composition data for each case. In each case the model setup is the same, except for assumptions about the background profile, which is also guided by observations. The case studies are numbered as in Methven et al. (2006), which also specifies each Lagrangian match time window in the aircraft data and presents maps of the trajectory ensembles. The section of the flight track that is used to initialise the location and composition of the trajectory ensemble is described for each case below. The simulations shown in this section are those that give the closest match with observations of all species downwind. The level of agreement in all species illustrates the capability of the model to simulate the air mass photochemical evolution. The variability within the ensembles is caused by differing initial conditions and differences in the path of each trajectory.

In order to quantify the degree to which a model can simulate net photochemical transformation, it is essential to consider the uncertainty in air mass composition associated with small scale variability. A long-range Lagrangian data set and model simulation have not been combined in this way before.

\subsection{Case 1: low altitude transport from USA to Portugal}

This is a case of transport from the USA to Portugal, at a height of approximately $0.5-1.5 \mathrm{~km}$. The ensemble was initialised from the NOAA WP-3D flight track between 20:4821:07 UT on 15 July (encompassing the Lagrangian match window, 20:57-21:05 UT, and neighbouring vertical profiles). Although there were no hydrocarbon measurements during this segment of the flight, the NASA DC8 was flying concurrently (within an hour and $0.35^{\circ}$ latitude, Methven et al., 2006) and so the DC8 hydrocarbon measurements are used in the initialisation. Downwind, this case was sampled by the FAAM BAe146 (19 and 25 July 2004) and by the DLR Falcon (22 July 2004). The model was run with photochemistry, dry and wet deposition and ensemble mixing. Based on the 25th, 50th and 75th percentile values of mixing rates inferred from hydrocarbon data by Arnold et al. (2007) and an observed plume depth of $1500 \mathrm{~m}, \kappa$ was set to $1.30 \mathrm{~m}^{2} \mathrm{~s}^{-1}$ for the control simulation, and to 0.91 and $1.56 \mathrm{~m}^{2} \mathrm{~s}^{-1}$ for the sensitivity tests (see Sects. 3.2.2 and 6 for details of how $\kappa$ is calculated based on observations). Emissions were switched off as the DLR observations suggest that the air mass was not influenced by emissions near Portugal, but the trajectories that pass close to the coast would otherwise pick up emissions from the 1 degree emissions grid. Elsewhere, the trajectories are over the ocean and would not encounter strong emissions in the model in any case (only $\mathrm{NO}_{\mathrm{x}}$ emissions from shipping lanes).

Figure 1 shows ensemble time series of different chemical species, coloured so that it is easier to distinguish between different trajectories. The colour of each trajectory depends on the time it was initialised (ordered from blue to red), with the red and orange trajectories matching with all the Lagrangian intercept locations. The aircraft observations are shown by black crosses. At the start of the simulation, there is a small net chemical loss of $\mathrm{O}_{3}$ during the night in the reference trajectory, and those surrounding it (red and orange trajectories). Then at dawn, there is net photochemical $\mathrm{O}_{3}$ production as there are elevated $\mathrm{O}_{3}$ precursor gases $\left(\mathrm{NO}_{\mathrm{x}}\right.$ and VOCs) in the air mass. There is a steady chemical loss of $\mathrm{O}_{3}$ during the day and almost no change during the night for the remainder of the simulation.

There is overlap between model and observations for CO, although the red and orange trajectories (which match with the downstream Lagrangian intercepts) overestimate $\mathrm{CO}$ by $\sim 10$ to 30 ppbv. Since emissions are weak in this case, CO only experiences reaction with $\mathrm{OH}$ and mixing. The model overestimates the $\mathrm{OH}$ in this case (Fig. 6), so the slow $\mathrm{CO}$ decrease is attributable to slower dilution by mixing in the model. In reality, vertical shear brings clean air aloft from the north which dilutes the polluted air mass from above (Fig. 6 of Methven et al. (2006) shows the vertical profile). However, in the model the trajectories only mix within the ensemble which does not include the cleaner air.

NO is underestimated by the model (possibly due to the lack of ship emissions), however it is only a small fraction of total $\mathrm{NO}_{\mathrm{y}}$. The largest component of $\mathrm{NO}_{\mathrm{y}}$ in this case is $\mathrm{HNO}_{3}$, which was not measured downstream. Figure 1e shows that the observed $\mathrm{NO}_{\mathrm{y}}$ (black crosses) lies within the upper end of the modelled $\mathrm{HNO}_{3}$ mixing ratios on day 204. The model PAN drops to values consistent with the observations on day 207, although the it is underestimated during the intercept on day 201. As with CO, this may be due to a lack of mixing with cleaner air.

As hydrocarbons were measured on a low time resolution by taking whole air samples, there are at most a few data points at each Lagrangian match, and the initial conditions are less certain than the other species. Despite this, the hydrocarbons in Fig. 1, ethane $\left(\mathrm{C}_{2} \mathrm{H}_{6}\right)$, acetylene $\left(\mathrm{C}_{2} \mathrm{H}_{2}\right)$ and propane $\left(\mathrm{C}_{3} \mathrm{H}_{8}\right)$, do show a similar rate of decay in the model and observations. 


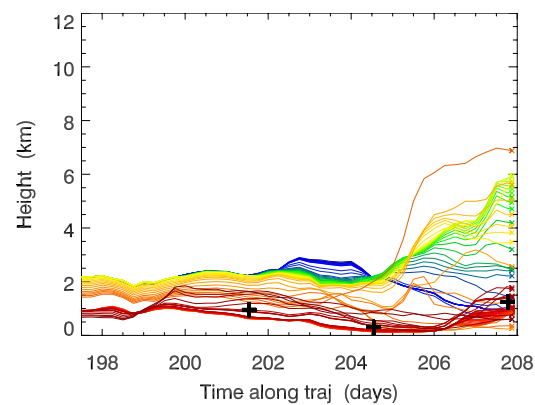

(a) Height

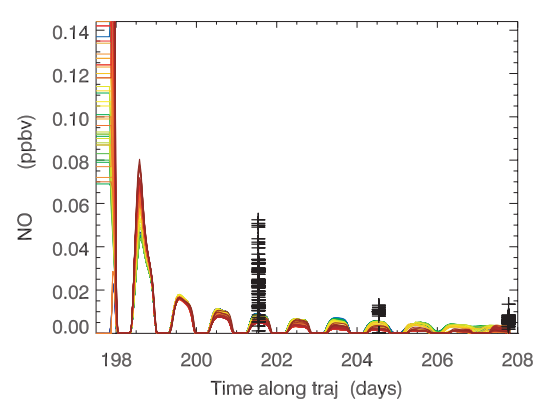

(d) NO

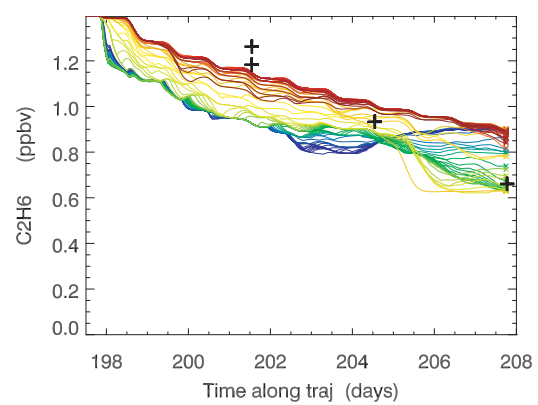

(g) $\mathrm{C}_{2} \mathrm{H}_{6}$

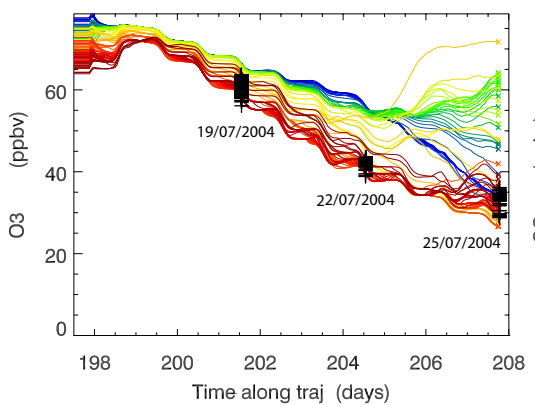

(b) $\mathrm{O}_{3}$

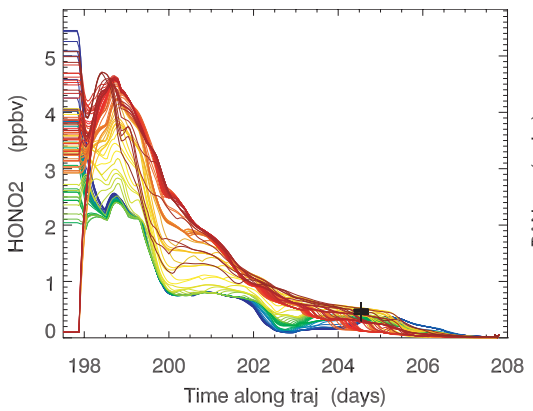

(e) $\mathrm{HNO}_{3}$

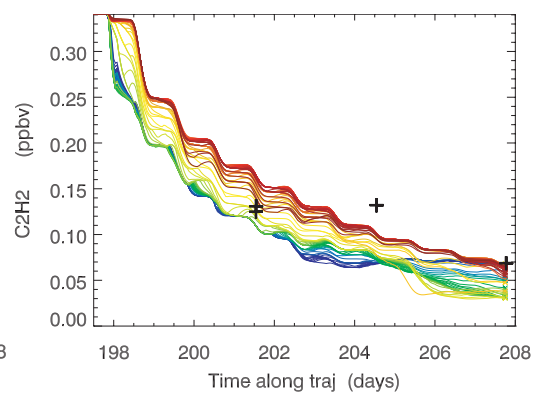

(h) $\mathrm{C}_{2} \mathrm{H}_{2}$

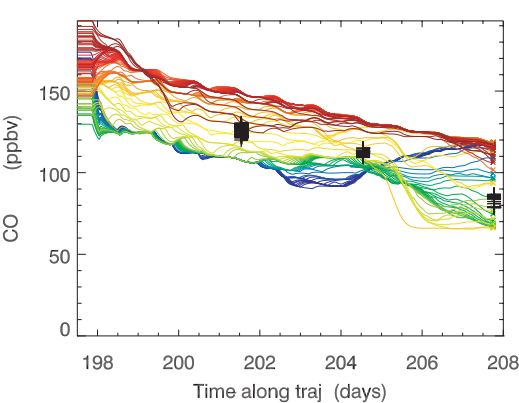

(c) $\mathrm{CO}$

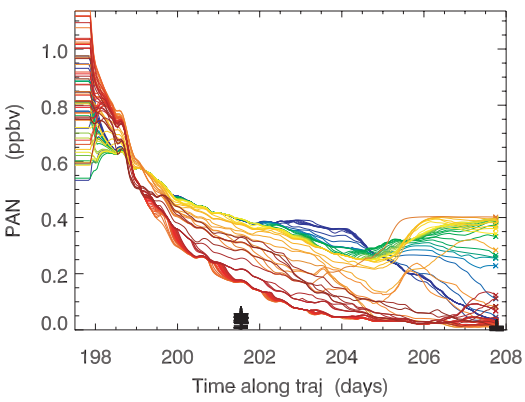

(f) PAN

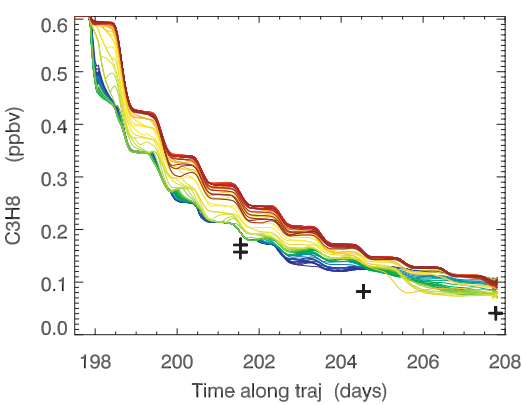

(i) $\mathrm{C}_{3} \mathrm{H}_{8}$

Fig. 1. Case 1 ensemble of trajectories for the control simulation. Trajectories are coloured by their release time from the flight track on 15 July 2004 so that individual trajectories can be distinguished. The red and orange trajectories pass nearest all downwind flight locations. Crosses show observations from Lagrangian aircraft intercepts defined by Methven et al. (2006). The time axis is days from 00:00 UT 1 January 2004. $\mathrm{NO}_{\mathrm{y}}$ observations from the DLR Falcon are shown at day 204 on the $\mathrm{HNO}_{3}$ plot.

\subsection{Case 2: high altitude transport of Alaskan fire emissions}

Case 2 sampled an air mass that had been polluted by emissions from boreal forest fires in Alaska. The details of how the pollutants were mixed into the air mass are not known, however once in the upper troposphere, the plume conserved its distinct composition. It was sampled by three different aircraft over a five day period. The first intercept was by the NASA DC8 on 18 July 2004, off the coast of Newfoundland. On 20 July, the FAAM BAe146 aircraft intercepted the plume in the mid-Atlantic north of the Azores. Finally, the DLR Falcon sampled the plume over Northern France on 23 July. The air mass descended slowly from $\sim 7 \mathrm{~km}$ altitude at the first
Lagrangian intercept, and then travelled to Europe at an altitude of 4-5 km (Fig. 2a).

Case 2 was modelled by Real et al. (2007) using a single trajectory version of CiTTyCAT that included the Fast-J photolysis code (Wild et al., 2000). It was initialised with observations and run along a representative trajectory, similar to the reference trajectory used here. Real et al. (2007) found that mixing was required to reproduce the observed evolution of the plume, and that the photolysis rates were affected by the presence of aerosol. They attributed the inplume $\mathrm{O}_{3}$ production primarily to PAN decomposition, and found that the simulated $\mathrm{O}_{3}$ production was sensitive to temperature and humidity. This indicates one limitation of using 


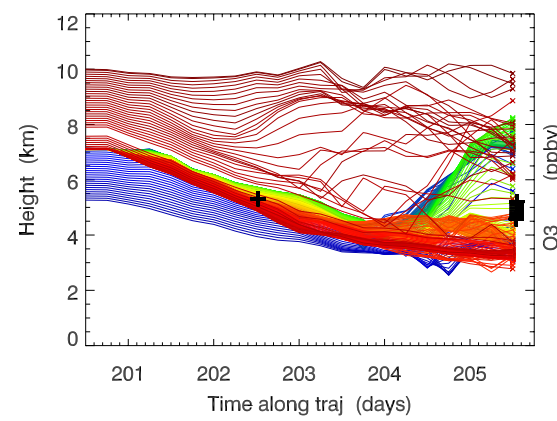

(a) Height

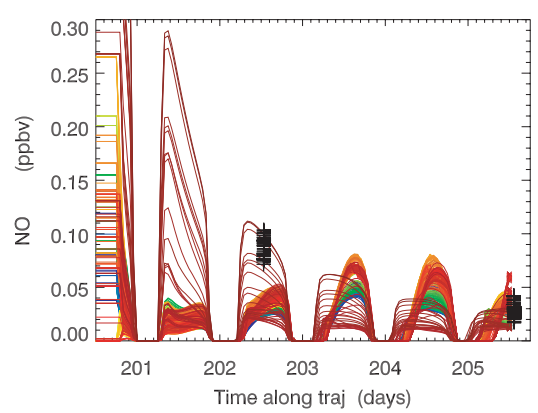

(d) $\mathrm{NO}$

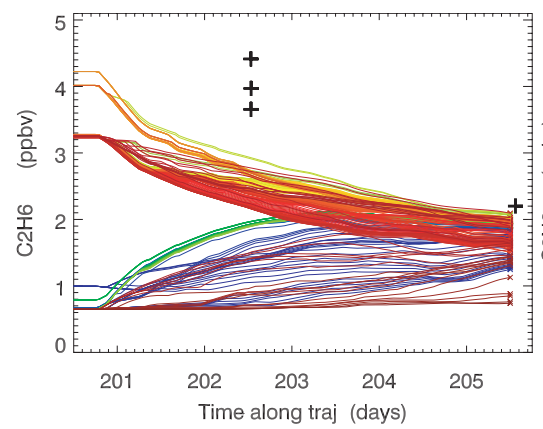

(g) $\mathrm{C}_{2} \mathrm{H}_{6}$

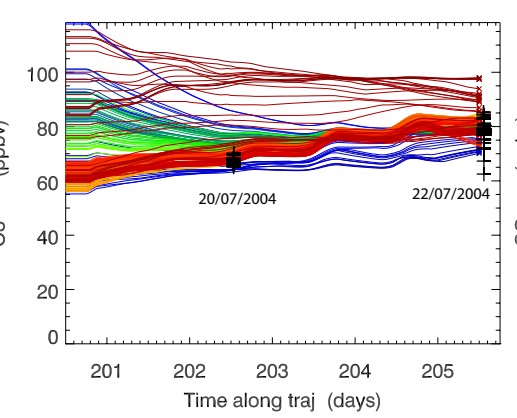

(b) $\mathrm{O}_{3}$

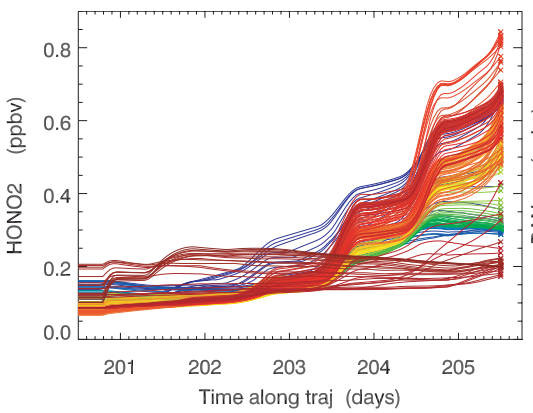

(e) $\mathrm{HNO}_{3}$

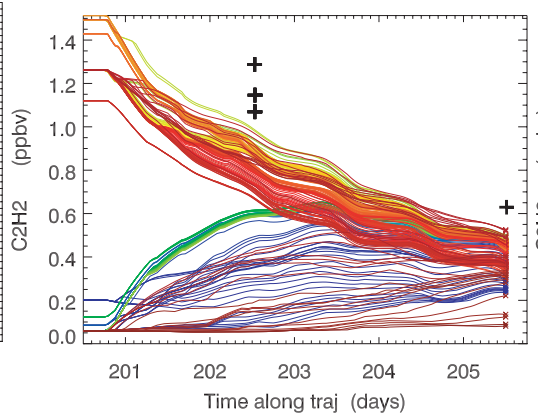

(h) $\mathrm{C}_{2} \mathrm{H}_{2}$

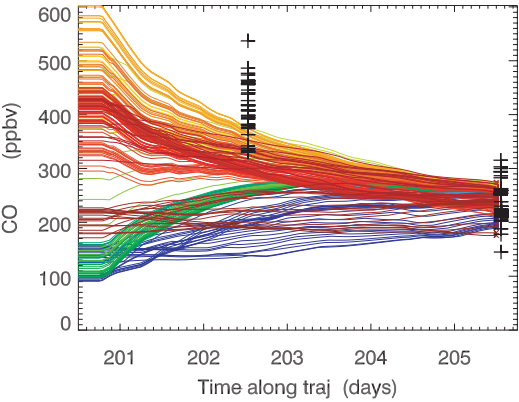

(c) $\mathrm{CO}$

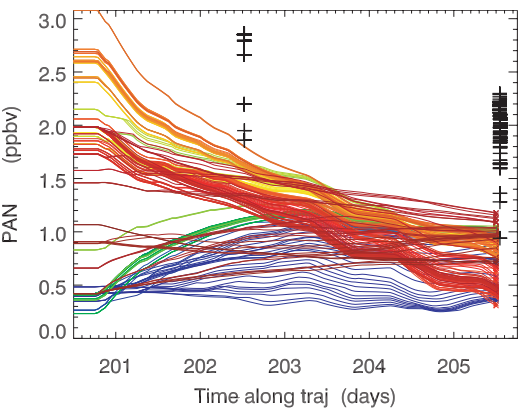

(f) PAN

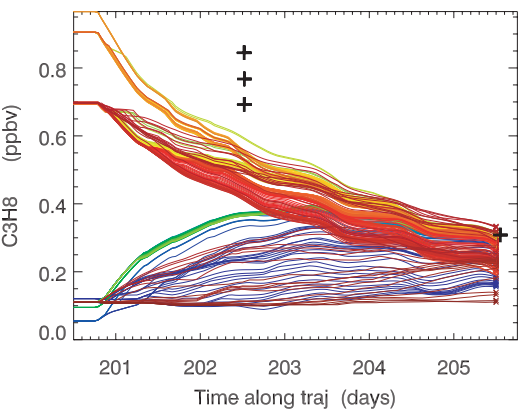

(i) $\mathrm{C}_{3} \mathrm{H}_{8}$

Fig. 2. Case 2 ensemble of trajectories for the control simulation. $\mathrm{NO}_{\mathrm{y}}$ observations from the DLR Falcon on day 205 are shown on the PAN plot. Trajectories are coloured by their release time from the flight track on 18 July 2004 so that individual trajectories can be distinguished. Blue trajectories are initialised immediately below the main plume; dark red above the main plume. Other details as in Fig. 1.

a single trajectory Lagrangian model, as the result will vary depending on the trajectory chosen.

Real et al. (2010) tackled this problem using an ensemble approach. Back trajectories from the aircraft flight tracks were calculated by Pisso et al. (2009) using a parcel model with a stochastic mixing parameterisation. Real et al. (2010) initialised CiTTyCAT with the MOCAGE (Model of Atmospheric Chemistry at Large Scale) global model concentrations, and simulated the chemical evolution forwards along all these trajectories. The average of all the simulations was compared to the Lagrangian observations, which represented mixing of all the air masses at the point of interception but not during transport. The model reproduced the $\mathrm{CO}, \mathrm{O}_{3}$ and $\mathrm{NO}_{\mathrm{y}}$ both in the plume and near the edges in this case. They conclude that this is a good approximation if the gradients are driven by synoptic winds, and is a suitable tool for studying layered structures in the free troposphere. They also advocated the addition of mixing during transport, as is carried out here.

The ensemble was initialised with NASA DC8 measurements between 18:27 and 19:08 UT on 18 July (day 200). This time window encompasses the Lagrangian match window (18:40 to 19:02 UT, during which the aircraft flew level at $\sim 7 \mathrm{~km}$ ) and measurements above and below. The model was run with photochemistry, an evolving background and a free tropospheric diffusion coefficient, $\kappa$, of $0.91 \mathrm{~m}^{2} \mathrm{~s}^{-1}$ for the control, and $\kappa=0.65 \mathrm{~m}^{2} \mathrm{~s}^{-1}$ and $1.56 \mathrm{~m}^{2} \mathrm{~s}^{-1}$ for sensitivity tests (calculated using mixing rates from Arnold et al. (2007) and the observed plume depth of $1500 \mathrm{~m}$ ). The layer spacing used in the mixing scheme $(\Delta z)$ is $500 \mathrm{~m}$ (larger than 
other cases to ensure that several trajectories are located in each layer), except for the sensitivity tests using $400 \mathrm{~m}$ and $600 \mathrm{~m}$.

Within the plume, there were a large number of missing aircraft data points for PAN, nitric acid and hydrocarbons. As these species are photochemically important, the mean was taken for all measurements of these species within the plume, defined to be when $\mathrm{CO}>280 \mathrm{ppbv}$, and this mean was used where there was missing data.

Figure $2 \mathrm{~b}$ indicates that the modelled $\mathrm{O}_{3}$ agrees well with the downstream observations, and is less influenced by mixing than other relatively long lived species such as $\mathrm{CO}$ and PAN. Methven et al. (2006) note that the fire plume was located within a low- $\mathrm{CO}$, high- $\mathrm{O}_{3}$ dry intrusion that had descended from close to the tropopause. This suggests that any turbulent mixing between the fire plume and the dry intrusion would not affect the $\mathrm{O}_{3}$ very much, but would dilute $\mathrm{CO}$ and hydrocarbons rapidly.

The initial mixing ratios of $\mathrm{CO}$ in the ensemble (which are the DC8 aircraft observations) are highly variable, ranging from as low as $100 \mathrm{ppbv}$ below the plume, up to a maximum of $600 \mathrm{ppbv}$ in the fire plume itself (see Fig. 2). A benefit of running an ensemble simulation is that this variability within the plume can be represented. Over time, the vertical mixing and photochemical decay of perturbations reduces the modelled ensemble spread which is similar to the observed spread in the two downstream match windows.

However, Fig. $2 \mathrm{c}$ shows that although the agreement is good on the last match (day 205), the model underestimates the $\mathrm{CO}$ mixing ratio during the second Lagrangian match (day 202). Real et al. (2007) noted that until day 202, the trajectories were gradually descending in clear air towards the southeast when they approached a stagnation point, changed direction and moved northeastwards with a warm conveyor belt. Pisso et al. (2009) inferred, by using ensembles of back trajectories perturbed stochastically to represent diffusion, a vertical diffusion coefficient of $\sim 0.35 \mathrm{~m}^{2} \mathrm{~s}^{-1}$ from the Lagrangian match on day 202, increasing to $\sim 2.7 \mathrm{~m}^{2} \mathrm{~s}^{-1}$ on day 205. In the simulations presented here, the mixing rate is constant $\left(\kappa=0.91 \mathrm{~m}^{2} \mathrm{~s}^{-1}\right)$ and the results overestimate the amount of CO dilution by day 202, but agree well on day 205. However, since PAN and the hydrocarbon mixing ratios observed at day 202 are as high as the upwind values used for initialisation, weaker diffusion to day 202 could not obtain consistent results.

Methven et al. (2006) noted that back trajectories released from the Lagrangian match on day 202 passed just above the level of the flight on day 200, and that the upstream intercept was on the lower edge of the most polluted air mass. Higher initial mixing ratios of $\mathrm{CO}$, as well as PAN and hydrocarbons would be consistent with the downstream Lagrangian matches, given decay both by mixing and reaction with $\mathrm{OH}$. Arnold et al. (2007) found that the hydrocarbon fingerprints also supported the hypothesis that the upstream aircraft flew through the more dilute flanks of the air mass (see Sect. 6 for a discussion of the method).

In this air mass, there is net photochemical $\mathrm{O}_{3}$ production which arises from the high mixing ratios of $\mathrm{NO}_{\mathrm{x}}$ and VOCs and low humidity. In addition, thermal decomposition of PAN is a source of $\mathrm{NO}_{\mathrm{x}}$ and also contributes to photochemical $\mathrm{O}_{3}$ production downstream. The loss of PAN and other precursors through mixing reduces the photochemical $\mathrm{O}_{3}$ production.

\subsection{Case 3: low altitude transport from USA to Ireland}

Case 3 tracked an anthropogenic pollution plume from the New York City area as it travelled across the North Atlantic to Ireland. Two meteorological balloons were released: one by the University of Massachusetts and one by NOAA. Although they were not released at the same time or location, they were at times very close, at about $10 \mathrm{~km}$ apart (see below). The NOAA WP-3D aircraft intercepted the plume on the 20, 21 and 22 July 2004 while it was travelling along the Gulf of Maine to Nova Scotia. The DLR Falcon then intercepted it off the west coast of Ireland on 25 July and over the English Channel on 26 July.

The NOAA WP-3D aircraft flew over the U. Mass balloon launch site about $20 \mathrm{~min}$ before the balloon was launched at approximately 20:30 UT on 20 July 2004 . Close to the balloon launch site, the aircraft flew straight and level in the plume, then flew a profile ascent and descent back into the polluted layer. Aircraft data showed that the anthropogenic pollution was confined to low levels (pressures above $940 \mathrm{hPa}$ ) with mixing ratios of up to approximately $110 \mathrm{ppbv}$ of $\mathrm{O}_{3}$ and $330 \mathrm{ppbv}$ of $\mathrm{CO}$, and a mean potential temperature of $297.3 \pm 0.5 \mathrm{~K}$ at pressures greater than $900 \mathrm{hPa}$. Potential temperature was measured by the balloon to be $299 \pm 1 \mathrm{~K}$ in the plume at $948 \mathrm{hPa}$, and $297 \pm 1 \mathrm{~K}$ at $980 \mathrm{hPa}$, suggesting that the aircraft and balloon were in the same air mass.

Forward trajectories from the balloon location do not coincide with the Lagrangian matches near Ireland. This discrepancy is because the balloon travelled in a low-level nocturnal jet, as identified by Riddle et al. (2006), which was not resolved in the ECMWF analysed wind fields used to calculate the trajectories. The jet was narrow, since the NOAA balloon which was only $10 \mathrm{~km}$ away and at a similar altitude when the U. Mass balloon was launched, was not caught in it and so followed the calculated trajectories more closely. Although the Lagrangian match window from Methven et al. (2006) had most trajectories reaching Ireland, it was an hour later on a WP-3D flight (21:05-21:30 UT), where the aircraft measured a similar potential temperature of $298 \pm 0.2 \mathrm{~K}$, but only $90.1 \pm 15.1 \mathrm{ppbv}$ of $\mathrm{O}_{3}$ and $199.7 \pm 30.1 \mathrm{ppbv}$ of $\mathrm{CO}$.

The trajectory ensemble used here includes some trajectories that reach the intercept near Ireland, by extending the time window (20:02-20:23 UT) to cover the flight over the balloon launch site, profile ascent to $\sim 3 \mathrm{~km}$ and descent back 


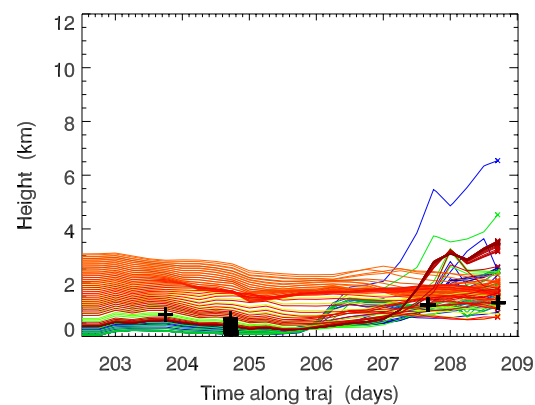

(a) Height

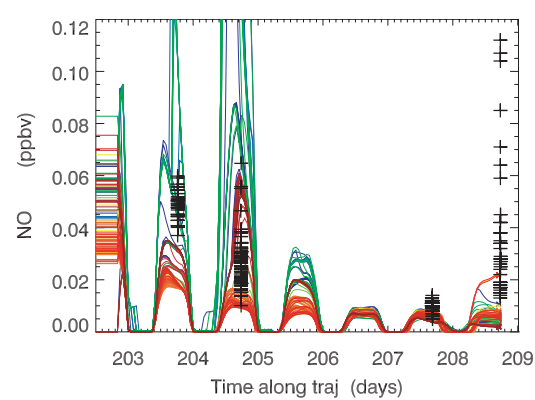

(d) $\mathrm{NO}$

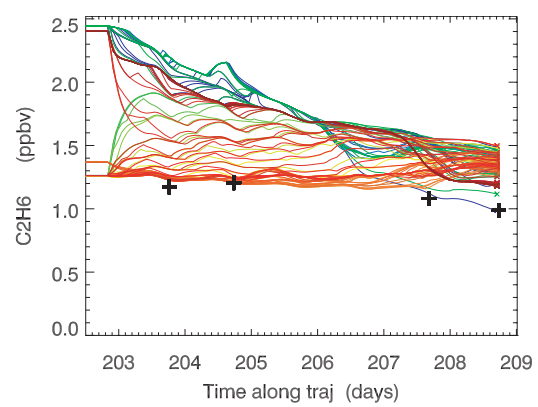

(g) $\mathrm{C}_{2} \mathrm{H}_{6}$

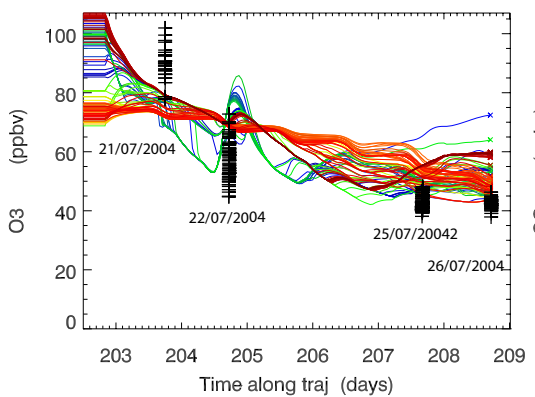

(b) $\mathrm{O}_{3}$

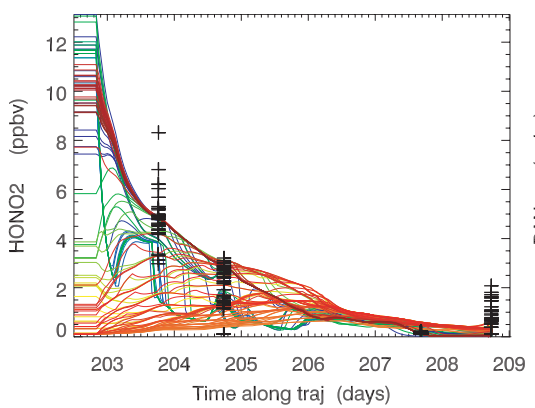

(e) $\mathrm{HNO}_{3}$

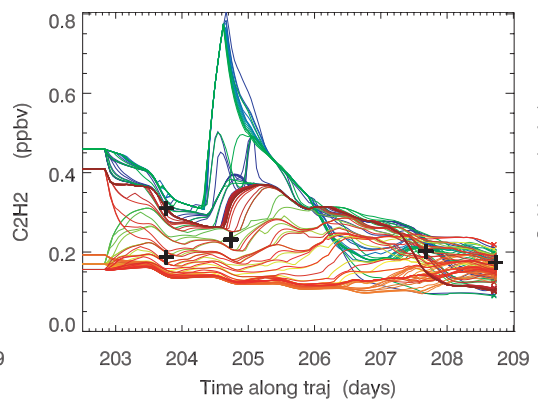

(h) $\mathrm{C}_{2} \mathrm{H}_{2}$

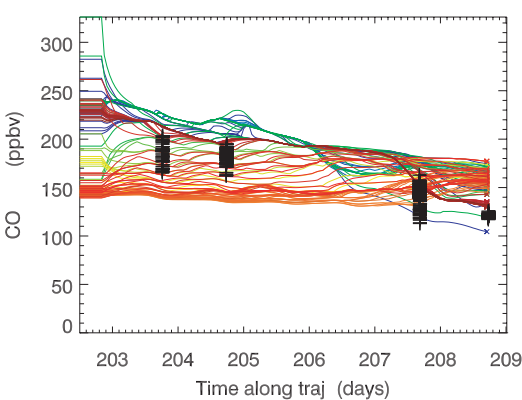

(c) $\mathrm{CO}$

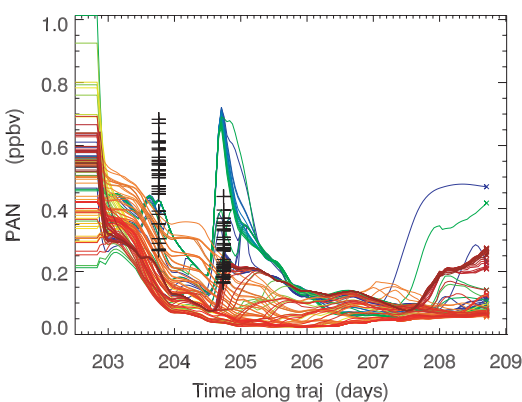

(f) PAN

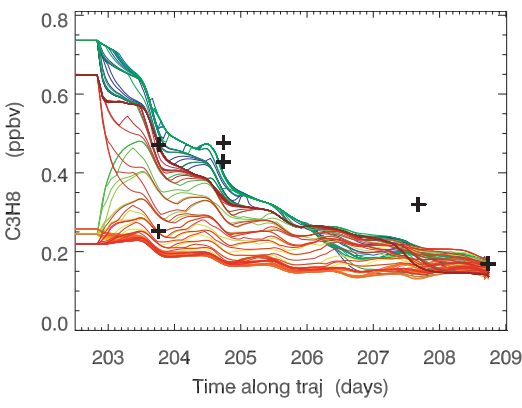

(i) $\mathrm{C}_{3} \mathrm{H}_{8}$

Fig. 3. Case 3 ensemble of trajectories for the simulation with doubled dry deposition. Trajectories are coloured by their release time from the flight track on 20 July 2004 so that individual trajectories can be distinguished. Dark green trajectories are initialised at the lowest altitudes, bright red at the highest. Other details as in Fig. 1.

into the polluted air mass below $\sim 500 \mathrm{~m}$. The initial conditions therefore include information about the plume composition and the profile above it.

Taking a polluted layer depth of $1500 \mathrm{~m}$ (as seen by the NOAA WP-3D on 21 July) and the 25,50 and 75 th percentile mixing rates from Arnold et al. (2007) give $\kappa=1.2 \mathrm{~m}^{2} \mathrm{~s}^{-1}$ for the control, and $\kappa=0.52 \mathrm{~m}^{2} \mathrm{~s}^{-1}$ and $\kappa=1.56 \mathrm{~m}^{2} \mathrm{~s}^{-1}$ for the sensitivity tests.

The time series in Fig. 3 is the simulation that obtains the best agreement with aircraft $\mathrm{O}_{3}$ measurements at day 207 (west of Ireland), based on the measurements at the Lagrangian matches (represented by black crosses). This is the doubled dry deposition simulation. The $\mathrm{O}_{3}$ dry deposition velocity over ocean in this simulation is $0.2 \mathrm{~cm} \mathrm{~s}^{-1}$ (twice that derived by Fairall et al. (2006) from observations during summer 2004), and all other dry deposition velocities were double their default values. The sensitivity tests are discussed in Sect. 5.

Mostly, the observations and modelled mixing ratios of the different chemical species overlap during the Lagrangian matches, and often have comparable variability. The modelled $\mathrm{O}_{3}$ is still overestimated by approximately $10 \mathrm{ppbv}$ during the final two matches, even with the use of a very high dry deposition velocity for $\mathrm{O}_{3}$ over the ocean $\left(0.2 \mathrm{~cm} \mathrm{~s}^{-1}\right)$. This may suggest that a physical $\mathrm{O}_{3}$ loss process is underestimated in the model.

Halogen chemistry can deplete $\mathrm{O}_{3}$ in the troposphere, particularly in the marine boundary layer, as ocean-atmosphere exchange is a key source of both bromine and iodine. The overestimate of $\mathrm{O}_{3}$ in the model after several days of transport at low altitudes over the Atlantic could be, in part, due to the absence of halogens in CiTTyCAT. Read et al. (2008) 
used a constrained box model to simulate $\mathrm{O}_{3}$ observations at Cape Verde, and found that the daytime depletion of $\mathrm{O}_{3}$ was in closer agreement with the observations when bromine and iodine chemistry was included, and gave an additional $\sim 1-$ 2 ppbv per day of $\mathrm{O}_{3}$ destruction. O'Brien et al. (2009) compared $\mathrm{O}_{3}$ measured at Cape Verde with simulations from a global CTM, and found that the inclusion of bromine chemistry reduced $\mathrm{O}_{3}$ mixing ratios by up to $5 \mathrm{ppbv}$ (in stable conditions). So it is likely that up to 5 ppbv more $\mathrm{O}_{3}$ could have been destroyed in the model by halogen chemistry. Other causes of the overestimate are that there is more uncertainty in the trajectories in this case, due to the low-level jet, and so the trajectories may pass over the wrong land or sea surface. And finally, it is likely that the plumes observed were not entirely representative of the air mass as a whole, the composition observed was highly variable.

Another obvious discrepancy is the NO on the final Lagrangian match in Fig. 3c. The DLR Falcon was flying along the English Channel on this day, and the high levels of NO are due to fresh anthropogenic emissions, probably from southern England or shipping lanes, which are not encountered in the model. The emissions were also detected in short lived hydrocarbons such as hexane (Methven et al., 2006). On the previous Lagrangian match before the air mass had reached Ireland, there is overlap between the modelled NO and the observations.

The cluster of trajectories coloured blue and green are distinct from the rest of the ensemble in Fig. 3. These trajectories were initialised at the lowest altitudes, while the aircraft was flying in the same anthropogenic plume as the balloon. They were initialised with relatively high mixing ratios of $\mathrm{CO}, \mathrm{O}_{3}, \mathrm{NO}_{\mathrm{y}}$ and hydrocarbons. They also remain at the lowest altitudes and are therefore most influenced by both surface emissions and dry deposition. This can be seen in the mixing ratios of $\mathrm{NO}_{\mathrm{x}}$, hydrocarbons and $\mathrm{CO}$ along the blue and green trajectories (as well as isoprene, not shown), which are all emitted as the trajectories crossed Nova Scotia on 22 July (day 204). The emission of $\mathrm{NO}_{\mathrm{x}}$ and VOCs gives rise to $\mathrm{O}_{3}$ production, which is greatest near the surface. A decrease in $\mathrm{O}_{3}$ from dry deposition followed by an increase from photochemical production can be seen in the blue and green trajectories in Fig. 3b on days 204 to 205.

Real et al. (2008) simulated case 3 using a single trajectory version of CiTTyCAT. Their simulation was improved by changing the mixing rate and background composition to represent different mixing regimes. Real et al. (2008) concluded that the majority of their $\mathrm{O}_{3}$ loss was attributable to photochemical loss and wet deposition of $\mathrm{HNO}_{3}$, which reduced the $\mathrm{NO}_{\mathrm{x}}$ available for $\mathrm{O}_{3}$ production. In their simulation, dry deposition was not as important because the single trajectory did not spend much time within the boundary layer.

However, in the ensemble simulation the effects of dry deposition to the surface are communicated vertically by exchange across the top of the boundary layer. As a result, there is less $\mathrm{HNO}_{3}$ (which experiences rapid dry deposition) avail- able for wet deposition. Adding wet deposition has a minor effect on $\mathrm{O}_{3}$ (less than $1 \mathrm{ppbv}$ difference at the final match). In summary, both studies result in a comparable loss of $\mathrm{O}_{3}$, but through different processes. The sensitivity of chemical and physical $\mathrm{O}_{3}$ change to model parameters is explored in the Sect. 5.

Lee et al. (2011) simulated the first two days of transport in case 3 using WRF-Chem, a mesoscale numerical weather prediction model coupled with chemistry, run with nested domains going up to $9 \mathrm{~km}$ horizontal grid spacing around the eastern seaboard region, where the flight on 20 July took place. They experimented with different initial and background chemical conditions (IC/BCs), and found that their choice of IC/BCs played an important role in determining the modelled $\mathrm{O}_{3}$ profile. They found a better agreement with ozonesonde profile observations using IC/BCs calculated by the MOZART-4 CTM (Model for Ozone and Related Chemical Tracers) instead of using prescribed profiles as IC/BCs. A sensitivity to the choice of background is also found here.

\subsection{Case 5: low altitude frontal-system export}

Case 5 is an example of low level transport just behind a cold front. The model was initialised from the NOAA WP-3D flight track between 18:34 and 18:54 UT on 27 July (encompassing the Lagrangian match window 18:39-18:54 UT and a profile ascent). Based on mixing rates inferred by Arnold et al. (2007) and an observed plume depth of $1150 \mathrm{~m}, \kappa$ was set to $0.70 \mathrm{~m}^{2} \mathrm{~s}^{-1}$ for the control simulation, and to 0.54 and $0.92 \mathrm{~m}^{2} \mathrm{~s}^{-1}$ for the sensitivity tests. The trajectories mostly travel as a coherent air mass, with the exception of some of the lowest altitude trajectories (coloured blue in Fig. 4). These experience emissions more strongly, resulting in a different chemical composition, and later their trajectories diverge from the rest of the ensemble.

The modelled and measured $\mathrm{O}_{3}$ mixing ratio and spread show a good agreement in this case (Fig. 4). However, the model overestimates $\mathrm{CO}$ (and in places the hydrocarbons), and there is a larger spread in the ensemble members for $\mathrm{CO}$ mixing ratio (even ignoring the blue trajectories, as they are not part of the plume of interest), compared to the measurements. This large variability is because the vertical gradient of $\mathrm{CO}$ is always very strong in the model, whereas the observations at the final intercept suggest the $\mathrm{CO}$ is almost uniform there. This is discussed further in Sect. 6.

On 31 July (day 213), the NO is underestimated by the model, but the next day the match is much closer. There is very little ensemble variation for NO in this case, although there is a wide variation in the mixing ratios in the sensitivity tests (not shown). The highest NO mixing ratio in the sensitivity tests is from a simulation with no wet deposition ( $\sim 18 \mathrm{pptv}$, compared to the mean observed NO of $\sim 14$ pptv), and the lowest is a simulation with a doubled scavenging coefficient. This suggests that wet deposition of $\mathrm{HNO}_{3}$ (the most soluble nitrogen species) is an important 


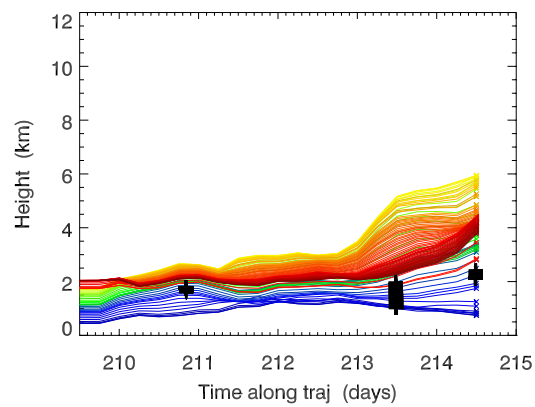

(a) Height

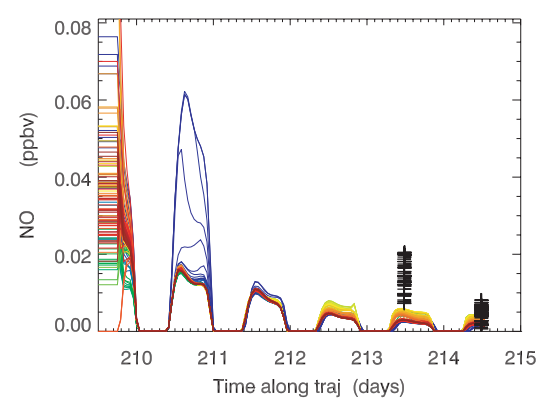

(d) $\mathrm{NO}$

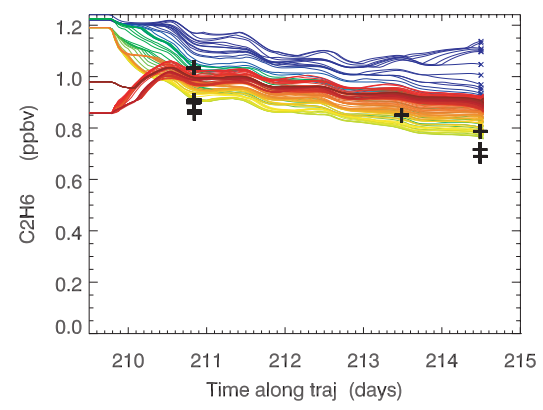

(g) $\mathrm{C}_{2} \mathrm{H}_{6}$

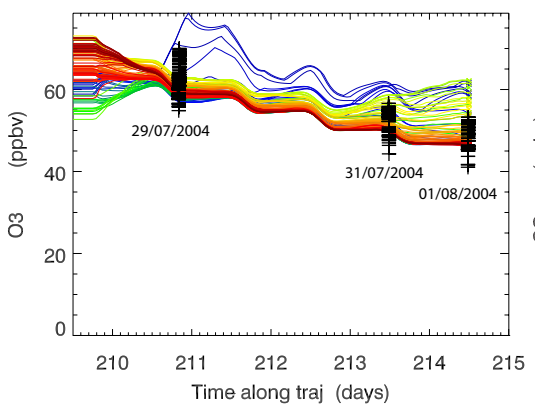

(b) $\mathrm{O}_{3}$

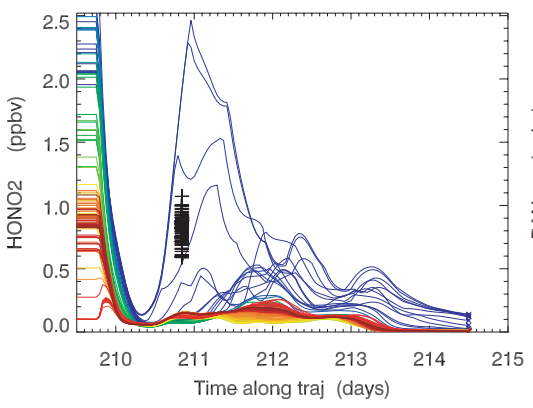

(e) $\mathrm{HNO}_{3}$

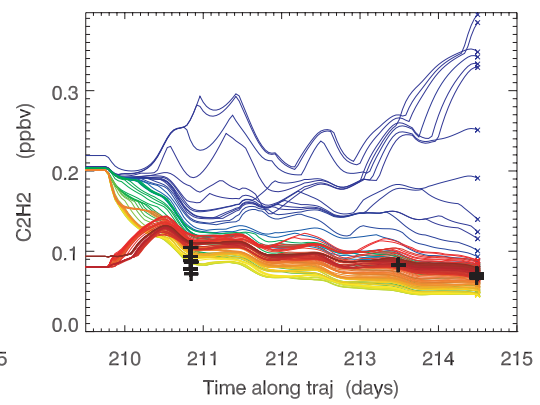

(h) $\mathrm{C}_{2} \mathrm{H}_{2}$

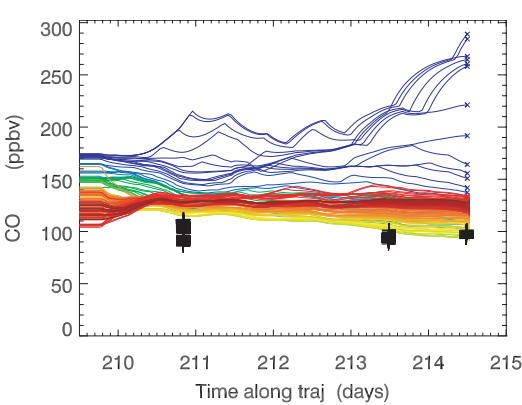

(c) $\mathrm{CO}$

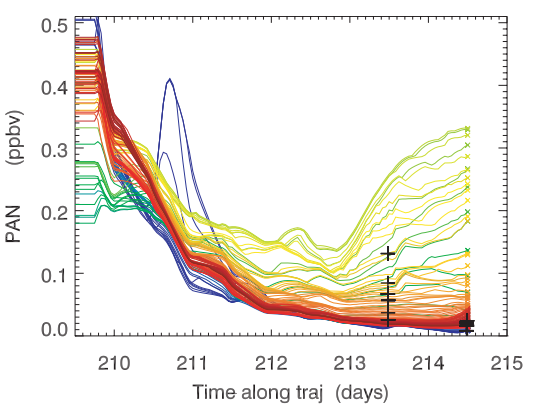

(f) PAN

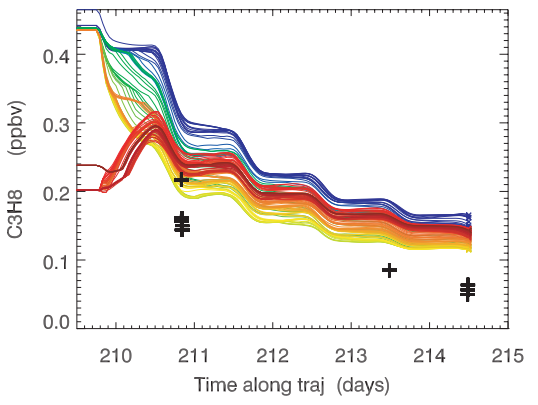

(i) $\mathrm{C}_{3} \mathrm{H}_{8}$

Fig. 4. Case 5 ensemble of trajectories for the control simulation. Trajectories are coloured by their release time from the flight track on 27 July 2004 so that individual trajectories can be distinguished. Blue trajectories remain lower in altitude than the main plume for the duration of this case. Other details as in Fig. 1.

process influencing NO mixing ratios in this case. The control simulation underestimates the $\mathrm{HNO}_{3}$ observation on day 210 (Fig. 4e). The sensitivity test with no wet deposition overestimates $\mathrm{HNO}_{3}$ at this point $(\sim 1.8 \mathrm{ppbv})$, suggesting that in this case the control simulation may be overestimating the losses from wet deposition. The precipitation field from the ECMWF model used to create the analysis is the rate of water reaching the ground from the whole column. Although a 3-D field for condensed-phase water mixing ratio (liquid plus ice) is calculated as part of the prognostic cloud scheme in the ECMWF model, the conversion to precipitation (rain and snow) and fall out is treated as an instantaneous process in each time-step. The scheme does calculate the fraction of precipitation reaching the ground from each level and a profile of evaporation, but this information is not output and therefore not available to use offline. In addition, the scavenging coefficient in the parameterisation of wet deposition used in CiTTyCAT (Penner et al., 1991) is based on the relationship between surface precipitation and regional nitrate budgets. This underestimate of $\mathrm{NO}_{\mathrm{y}}$ is however not the most important factor for $\mathrm{O}_{3}$ mixing ratio. Sensitivity tests for cloud cover (completely clear or completely cloudy) resulted in the largest change in $\mathrm{O}_{3}$ mixing ratio compared to the control simulation (Fig. 5).

\section{Sensitivity to physical parameters}

Simulations to test the model response to varying different model parameters were carried out for all cases (see Table 1). A discussion of the processes influencing the model results for these case studies follows. The range of 


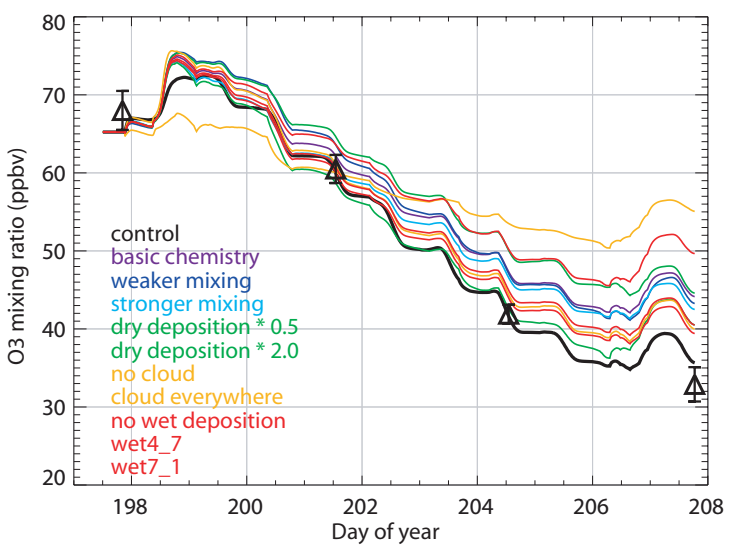

(a) Case 1

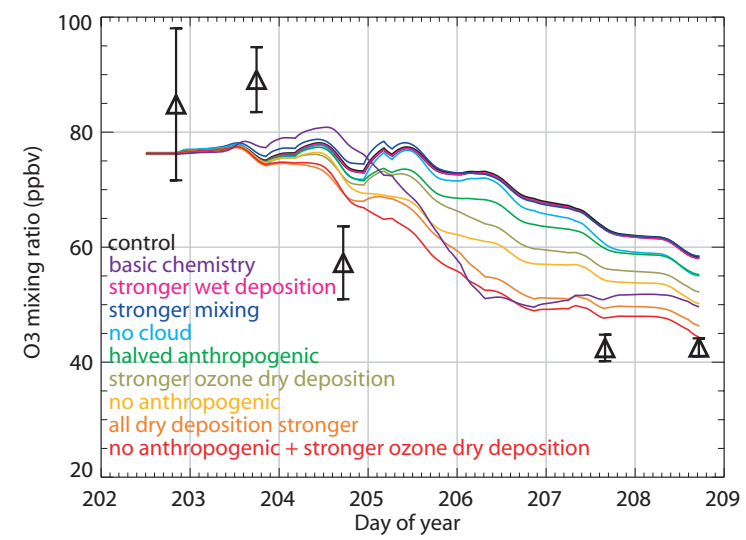

(c) Case 3

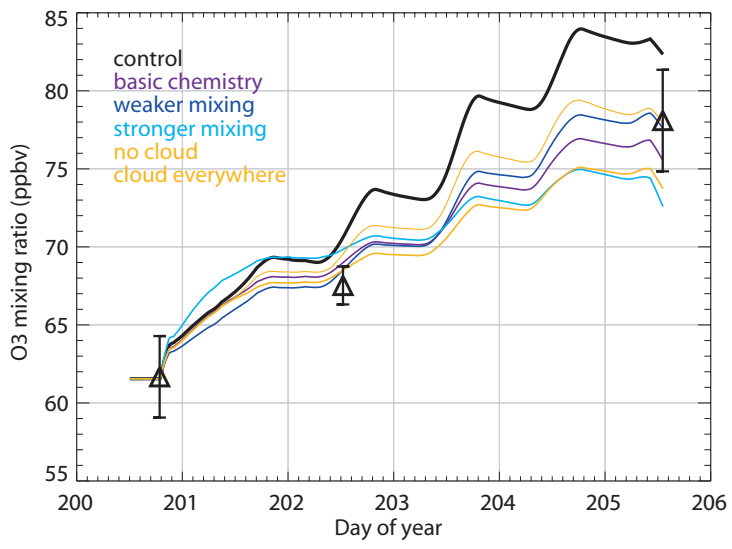

(b) Case 2

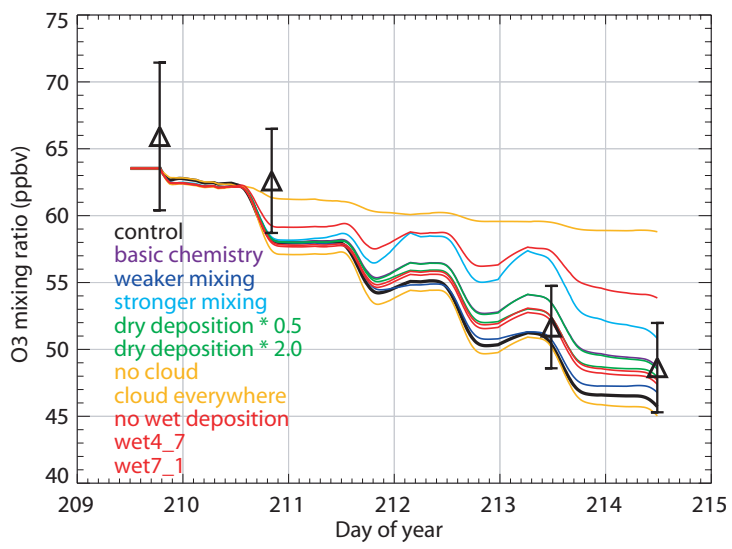

(d) Case 5

Fig. 5. $\mathrm{O}_{3}$ mixing ratio along the reference trajectory for each case. The control simulation (black) is shown alongside sensitivity tests as labelled. See Table 1 for details. Mean \pm standard deviation aircraft observations taken during the Lagrangian match windows are shown by triangles and error bars. The sensitivity tests for cases 1,2 and 5 were performed with an earlier version of ensemble CiTTyCAT (with a more basic chemistry scheme, see Sects. 3.2 and 5 for details). The control simulation with the basic chemistry is shown in purple.

parameter variations is guided by uncertainties deduced from ICARTT observations (mixing and dry deposition) or the literature (emissions and wet deposition), except for the cloud cover tests (no cloud versus complete cloud cover). The cloud tests represent the extreme bounds on photolysis rates. The EDGARFT2000 anthropogenic emissions inventories are quoted with a $50 \%$ uncertainty for $\mathrm{CO}, \mathrm{NO}_{\mathrm{x}}$ and $\mathrm{CH}_{4}$, and $100 \%$ uncertainty for NM-VOCs (Olivier et al., 2005) so sensitivity tests for the anthropogenic emissions were run by multiplying all anthropogenic emissions by 0.5 or 1.5 .

Two versions of the chemical scheme are included to gauge the sensitivity to mechanism complexity. The sensitivity tests for case 3 were performed using a version of the model including the improved isoprene chemistry scheme described by Pugh et al. (2010), shown in black and labelled control in all cases. A simulation using a reduced chemistry scheme (as used by Real et al., 2008) is shown in purple and labelled basic chemistry. For cases 1, 2 and 5 the basic scheme was used for the sensitivity tests, as the same broad features are present in the control and basic chemistry simulations. There are no tests in this work related to parametric uncertainty in the chemical mechanism, however Ridley and Arnold (2009) have explored the uncertainty in chemical reaction rate co-efficients for these cases using CiTTyCAT with a Monte-Carlo methodology.

Figure 5 shows the $\mathrm{O}_{3}$ mixing ratio along the reference trajectory (which passes through each Lagrangian match location) for each of the sensitivity tests. The mean and standard deviation of the aircraft observations during each match window are shown by the black triangles and whiskers.

The spread in the sensitivity tests represents uncertainty related to parametric and structural uncertainty in the model. This is in contrast to the variability within each ensemble, which is due to different initial conditions and following different trajectory paths.

In cases 1 and 5, there is agreement between the control simulation (black in Fig. 5) and the observations in most matches. In both of these cases, changing the cloud cover 
Table 1. Sensitivity tests for the ITCT-Lagrangian 2004 cases.

\begin{tabular}{|c|c|c|}
\hline Parameter & Control value & Perturbed values \\
\hline \multicolumn{3}{|c|}{ Case 1} \\
\hline$\kappa\left(\mathrm{m}^{2} \mathrm{~s}^{-1}\right)$ & 1.30 & Weak mixing: 0.91; Strong mixing: 1.56 \\
\hline Dry deposition velocities & See Pugh et al. (2012) & Control $\times 0.5 ;$ Control $\times 2$ \\
\hline Scavenging coefficients $\left(\mathrm{cm}^{-1}\right)$ & Convective: 4.7 , stratiform: 2.4 & $\begin{array}{l}\text { Both } 0 \text {; Convective: } 4.7 \mathrm{~cm} \text {, stratiform: } \\
0 \text {; Convective: } 7.1 \mathrm{~cm} \text {, stratiform: } 0\end{array}$ \\
\hline Cloud cover & Climatological & No cloud; $100 \%$ cloudy in all cloud layers \\
\hline$\Delta z(\mathrm{~m})$ & 200 & None. \\
\hline \multicolumn{3}{|c|}{ Case 2} \\
\hline$\kappa\left(\mathrm{m}^{2} \mathrm{~s}^{-1}\right)$ & 0.91 & Weak mixing: 0.65; Strong mixing: 1.56 \\
\hline Cloud cover & Climatological & No cloud; $100 \%$ cloudy \\
\hline$\Delta z(\mathrm{~m})$ & 500 & $400 ; 600$ \\
\hline \multicolumn{3}{|c|}{ Case 3} \\
\hline$\kappa\left(\mathrm{m}^{2} \mathrm{~s}^{-1}\right)$ & 1.2 & Weak mixing: 0.52; Strong mixing: 1.56 \\
\hline Dry deposition velocities & $\begin{array}{l}\mathrm{O}_{3} \text { over the ocean }=0.03 \mathrm{~cm} \mathrm{~s}^{-1} . \text { Full list of } \\
\text { dry deposition velocities in Pugh et al. (2012). }\end{array}$ & $\begin{array}{l}\text { As control, except } \mathrm{O}_{3} \text { over the ocean }=0.1 \mathrm{~cm} \mathrm{~s}^{-1} \\
\text { (Fairall et al., 2006); Control } \times 2 \text {, except } \mathrm{O}_{3} \text { over } \\
\text { the ocean }=0.2 \mathrm{~cm} \mathrm{~s}^{-1}\end{array}$ \\
\hline Scavenging coefficients $\left(\mathrm{cm}^{-1}\right)$ & Convective: 4.7 , stratiform: 2.4 & Both 0; Convective: 7.1, stratiform: 3.6 \\
\hline Anthropogenic emissions & EDGARFT2000 & None; Control $\times 0.5 ;$ Control $\times 1.5$ \\
\hline $\begin{array}{l}\text { Dry deposition and no } \\
\text { anthropogenic emissions }\end{array}$ & $\begin{array}{l}\text { Pugh et al. (2012) for dry deposition references, } \\
\text { EDGARFT2000 emissions }\end{array}$ & $\begin{array}{l}\text { Dry deposition as control, except } \mathrm{O}_{3} \text { over the ocean } \\
=0.1 \mathrm{~cm} \mathrm{~s}^{-1} \text {. No anthropogenic emissions. }\end{array}$ \\
\hline Cloud cover & Climatological & No cloud; $100 \%$ cloudy \\
\hline$\Delta z(\mathrm{~m})$ & 200 & $100 ; 300$ \\
\hline \multicolumn{3}{|c|}{ Case 5} \\
\hline$\kappa\left(\mathrm{m}^{2} \mathrm{~s}^{-1}\right)$ & 0.70 & Weak mixing: 0.54; Strong mixing: 0.92 \\
\hline Dry deposition velocities & See Pugh et al. (2012) & Control $\times 0.5 ;$ Control $\times 2$ \\
\hline Scavenging coefficients $\left(\mathrm{cm}^{-1}\right)$ & Convective: 4.7 , stratiform: 2.4 & $\begin{array}{l}\text { 0; Convective: } 4.7 \text {, stratiform: } 0 \text {; Convective: } 7.1 \text {, } \\
\text { stratiform: } 0\end{array}$ \\
\hline Cloud cover & Climatological & No cloud; $100 \%$ cloudy \\
\hline$\Delta z(\mathrm{~m})$ & 200 & None. \\
\hline
\end{tabular}

to completely clear or completely cloudy for the duration of the run (yellow lines) has one of the largest impacts of all the sensitivity tests. This is not surprising, as these are the two extremes of the cloud fields, whereas the other tests that change mixing and deposition parameters are not such extreme perturbations. In cases 1 and 5, having complete cloud cover attenuates the actinic flux at the location of the low level trajectories, so the photochemistry is less active and the $\mathrm{O}_{3}$ loss is weaker than in other simulations. In case 2, the opposite is true, as light is reflected off the clouds below the plume, and there is an increase in the net photochemical $\mathrm{O}_{3}$ production when there is more cloud cover.

In cases 1 and 5 , changes to the wet deposition (red lines in Fig. 5a and 5d) can cause differences in $\mathrm{O}_{3}$ of the order \pm 5 ppbv, with the dry deposition tests (green) having a similar effect in case 1 and less of an impact in case 5 where the air masses are well above the boundary layer. This is in contrast to case 3 (Fig. 5c), in which wet deposition had a minor influence (pink) relative to dry deposition (light green). Modifying the mixing rate (dark blue) only affects the $\mathrm{O}_{3}$ by up to a few ppbv. The more influential part of the mixing scheme is the background.

The control simulation (black line) for case 3 overestimated the final $\mathrm{O}_{3}$ by $\sim 15$ ppbv compared to the observations. Additional tests were performed to try and find a better agreement. Only results from the case 3 sensitivity tests that lowered $\mathrm{O}_{3}$ are shown here. Fairall et al. (2006) derived $\mathrm{O}_{3}$ dry deposition velocities based on data from the MBL during the ICARTT 2004 field campaign, calculating values up to $0.1 \mathrm{~cm} \mathrm{~s}^{-1}$ with a median of $0.044 \mathrm{~cm} \mathrm{~s}^{-1}$. A sensitivity test was performed with the $\mathrm{O}_{3}$ dry deposition velocity increased to $0.1 \mathrm{~cm} \mathrm{~s}^{-1}$ (usually $0.03 \mathrm{~cm} \mathrm{~s}^{-1}$ ) over the ocean (stronger $\mathrm{O}_{3}$ dry deposition, light green), which improved the $\mathrm{O}_{3}$ agreement. A simulation where dry deposition velocities of all species were doubled (and $\mathrm{O}_{3}$ dry deposition doubled to $0.2 \mathrm{~cm} \mathrm{~s}^{-1}$ ) was also carried out (all dry deposition 


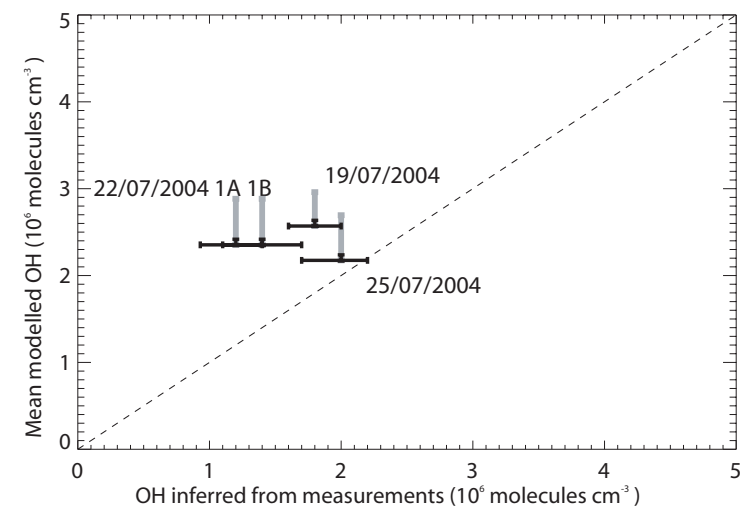

(a) Case 1

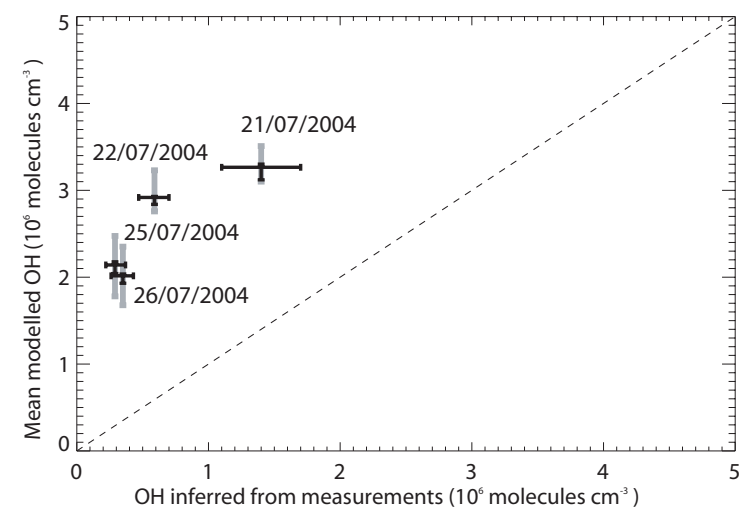

(c) Case 3

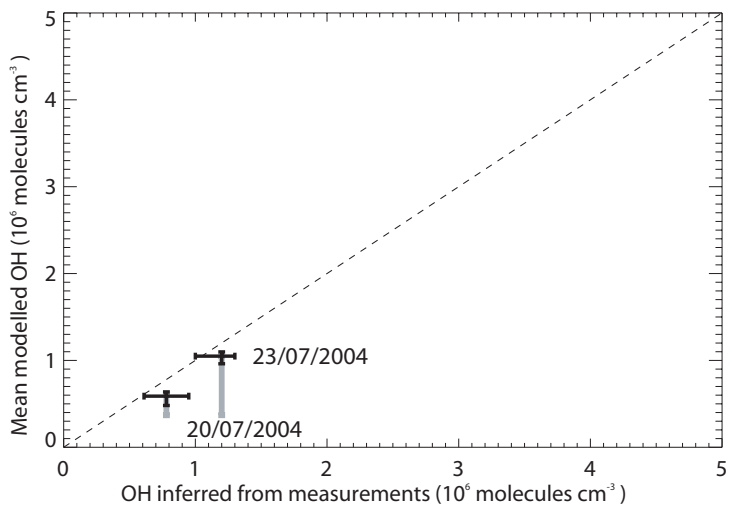

(b) Case 2

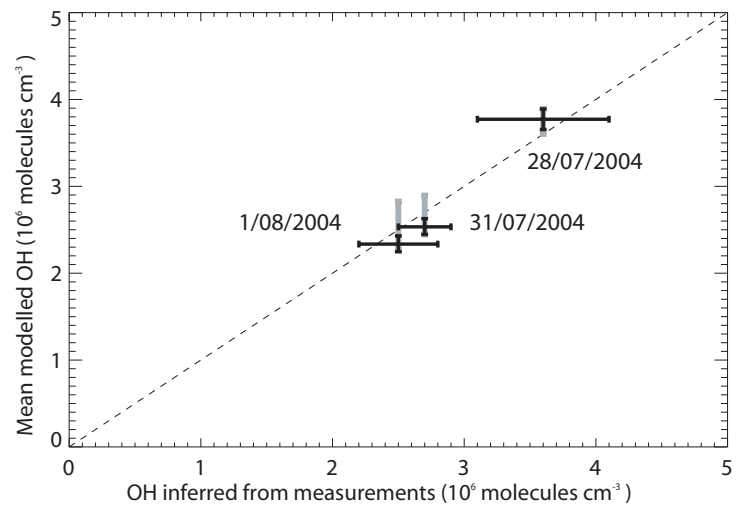

(d) Case 5

Fig. 6. Comparison of modelled $\overline{[\mathrm{OH}]}$ with that inferred from hydrocarbon measurements by Arnold et al. (2007). The 25th and 75th percentiles were calculated from the time-average $\mathrm{OH}$ along the trajectories within each ensemble. The black bars show the resulting range for the control ensemble (doubled dry deposition for case 3). The grey bars show the minimum and maximum of the results from all sensitivity experiments. Ensemble results are filtered such that only trajectories that reach the final Lagrangian match location are included here.

stronger, orange), which brought the $\mathrm{O}_{3}$ yet closer to the observations.

As this case does encounter significant emissions, sensitivity tests to vary the emissions were carried out. Halving the anthropogenic emissions (dark green) had a similar net effect on $\mathrm{O}_{3}$ as assuming clear skies (light blue). Removing the anthropogenic emissions (yellow) reduced $\mathrm{O}_{3}$ even further, although the reference trajectory still overestimated the $\mathrm{O}_{3}$. No emissions combined with the Fairall et al. (2006) dry deposition velocity for $\mathrm{O}_{3}$ (red) brings the $\mathrm{O}_{3}$ even closer to the observations. However, removing all anthropogenic emissions causes an underestimation of $\mathrm{NO}_{\mathrm{y}}$ (not shown), and therefore the best case shown in Fig. 3 is the simulation with doubled dry deposition, and default emissions.

\section{Evaluation of model against Lagrangian measurements}

A direct comparison between the model and the observations is shown in Figs. 6, 7 and 8 for $\overline{[\mathrm{OH}]}, \mathrm{O}_{3}$ and $\mathrm{CO}$, where the black bars show the 25th, 50th and 75th percentiles of the observations and the control ensemble simulations evaluated at the Lagrangian match windows (the doubled dry deposition run is used in place of the control for case 3). The 25th and 75th percentiles were calculated for each of the sensitivity tests, and the range of these results are shown by the grey bars, and therefore show the variability from within each ensemble, as well as from the perturbations to the model parameters. In each case, the trajectories considered to be outside of the main plume are excluded in the statistics. For cases 1 and 3, only trajectories that reach the region of the final Lagrangian match (latitudes south of $45^{\circ} \mathrm{N}$ for case 1; latitudes south of $55^{\circ} \mathrm{N}$ and longitudes east of $10^{\circ} \mathrm{W}$ for case 3 ) are included. For case 2, only trajectories initialised at 7.0 to $7.5 \mathrm{~km}$ altitude are included. For case 5, only trajectories initialised above $1 \mathrm{~km}$ are included. For the low altitude cases (1, 3 and 5), the cloud cover tests are excluded from the grey error bars in Fig. 6, as they give rise to an unrealistic perturbation to the $\overline{[\mathrm{OH}]}$. Case 2 contained higher loads of aerosol that may have affected the radiation budget, so the cloud simulations are retained. For the match on 22 July, 
Arnold et al. (2007) state two calculated values for $\overline{[\mathrm{OH}]}$, labelled as $1 \mathrm{~A}$ and $1 \mathrm{~B}$.

Comparing $\overline{[\mathrm{OH}]}$ inferred from observations and from the model is a way to evaluate the overall photochemical activity. The short lifetime and dependence on sunlight of $\mathrm{OH}$ means that it is highly variable in space and time, and it is therefore more meaningful to take an average over a long time period as a measure of the oxidising capacity of an air mass. Arnold et al. (2007) have inferred the $\overline{[\mathrm{OH}]}$ between the upstream intercept and each subsequent intercept for each of the Lagrangian cases. Their Bayesian inference is based on having a good representation of the composition upstream and downstream, and calculating the $\overline{[\mathrm{OH}]}$ and mixing rate that would give the correct photochemical activity to account for the transformation. The method refines a prior distribution using a model for hydrocarbon loss through reaction with $\mathrm{OH}$ and dilution with the background to give a posterior distribution that relates to the upstream and downstream observations equally. Many hydrocarbons with different reactivities were considered to sharpen the estimates. Arnold et al. (2007) also showed that the matches were strong in cases 2 and 5, in the sense that the hydrocarbon fingerprint provided a strong constraint on the posterior $\overline{[\mathrm{OH}]}$, and weakest in case 3 . This explains why the agreement between modelled and inferred $\overline{[\mathrm{OH}]}$ is best in cases 2 and 5 (Fig. 6), and least good for case 3 . In case 3, the variability in hydrocarbon mixing ratios was large in the upwind region near the East Coast USA. The upwind Lagrangian match time window had much lower butane mixing ratios than other parts of the plume at that time and also lower than observed west of Ireland (even though the other alkanes were consistent with loss by $\mathrm{OH}$ reaction and dilution). Therefore it is likely that mixing increased butane in the target air mass. This missing process leads to an underestimate of $\overline{[\mathrm{OH}]}$ by Arnold et al. (2007), not reflected in the "error bars".

Figure 7 shows that the $\mathrm{O}_{3}$ evolution is reproduced in the model. Case 5 shows the best agreement, as the Lagrangian matches were strong, and there is less influence from the surface compared to cases 1 and 3 . Where there is a greater influence from the surface (cases 1 and 3), there is a wider spread in the sensitivity tests (grey bars) than the higher altitude cases (2 and 5).

In terms of oxidising capacity, case 2 is quite different from the other cases, which is to be expected as it is dry, at high altitude and contains high $\mathrm{CO}$ mixing ratios from the forest fire emissions. The main $\mathrm{OH}$ formation mechanism is through photolysis of $\mathrm{O}_{3}$ in the presence of water vapour, so less $\mathrm{OH}$ is formed compared to the other cases, which are in the lower troposphere. The air mass is driest in the first half of the transport, which is consistent with lower $\overline{[\mathrm{OH}]}$ up until 20 July compared to 23 July. In addition, reaction with $\mathrm{CO}$ is one of the dominant sinks of $\mathrm{OH}$, therefore the high $\mathrm{CO}$ mixing ratios (Fig. 8) from the fire emissions in this case will further reduce $\mathrm{OH}$ mixing ratios. For $\mathrm{CO}$, it is likely that the initial conditions did not capture the most polluted part of the plume, leading to an underestimate in $\mathrm{CO}$ initially (as discussed in Sect. 4.2).

In the low altitude transport cases, the $\mathrm{CO}$ is generally overestimated by the model (Fig. 8), even when the joint Lagrangian match in terms of trajectories and hydrocarbon fingerprints is good. Assuming that the oxidation of $\mathrm{CO}$ by $\mathrm{OH}$ is reasonably represented (as the $\mathrm{OH}$ has a reasonable agreement with observations) the only other non-negligible production or loss of $\mathrm{CO}$ is through mixing.

When parameterising mixing in a Lagrangian model, there are two key elements to consider: the rate of mixing, and the surroundings with which the trajectory is mixing. As the mixing rates here are based on observations for each case, and perturbing them does not make a large difference, the mixing rates are unlikely to be the greatest source of error.

In CiTTyCAT, the background is parameterised as if the ensemble of trajectories remained coherent in the horizontal. This means that the background air travels with the main polluted air mass, and therefore was also polluted from the initial conditions. However, in reality the trajectories at lower altitudes would travel slower; a pollution plume travelling above the marine boundary layer (MBL) would run over an older, cleaner MBL. A cluster analysis of ICARTT $2004 \mathrm{ob}-$ servations by Lewis et al. (2007) finds CO of $\sim 64 \mathrm{ppbv}$ for the MBL cluster and $\sim 130$ ppbv for the lower level outflow cluster. The lower level background in the simulations presented here has similar or higher $\mathrm{CO}$ to the low level outflow cluster, which is why the CO is systematically overestimated. In most cases, cleaner air is also brought across aloft through differential advection, unlike in the model.

\section{$\Delta \mathrm{O}_{3}$
partitioned by process}

In order to examine the different chemical and physical processes influencing $\mathrm{O}_{3}$, the model tendencies due to different processes are partitioned, accumulated and output for the reference trajectory. The time-integrated tendency diagnostics are calculated using the following equation:

$\Delta c_{i}=\Delta c_{i-1}+\mathrm{d} t \times \frac{\left(\frac{D c}{D t}\right)_{i-1}+\left(\frac{D c}{D t}\right)_{i}}{2}$,

where $\left(\frac{D c}{D t}\right)_{i}$ is the tendency at time step $i$ for a particular process: chemical production, chemical loss, dry deposition, wet deposition or mixing. $\Delta c_{i}$ is the time-integrated tendency from the start up to time step $i$. The time interval is $\mathrm{d} t$, which is $300 \mathrm{~s}$ in the simulations presented here. Note that the ODE integrator uses a shorter variable time-step to achieve a specified tolerance on the coupled solution, but this midpoint approximation to the rates is sufficient for diagnostics. 


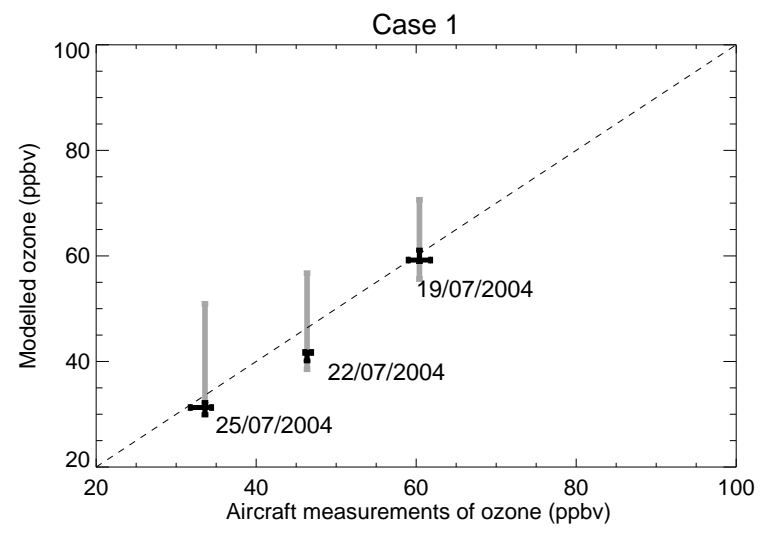

(a) Case 1

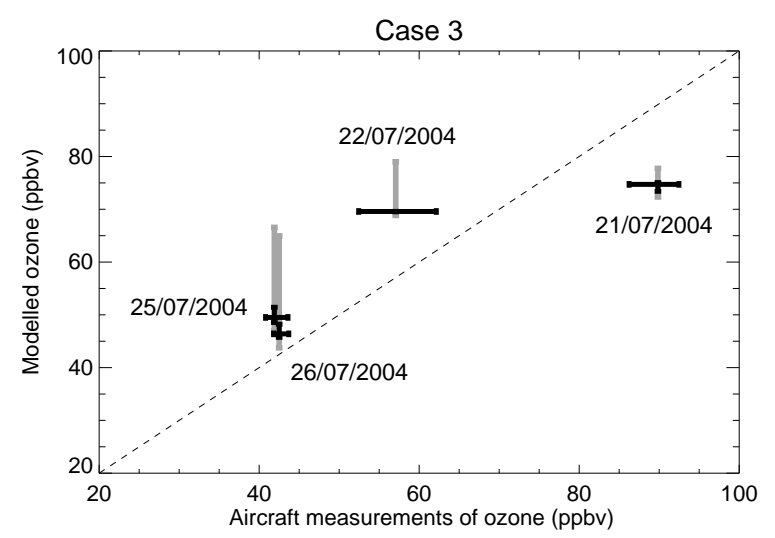

(c) Case 3

Fig. 7. Comparison of modelled and observed $\mathrm{O}_{3}$, as Fig. 6 .

\section{1 $\Delta \mathrm{O}_{3}$ partitioned by process in the sensitivity tests}

Figure 9 shows the time-integrated $\mathrm{O}_{3}$ tendencies $\left(\Delta \mathrm{O}_{3}\right)$ partitioned into chemical $\left(\Delta \mathrm{O}_{3 \mathrm{chem}}\right.$, solid lines) and physical ( $\Delta \mathrm{O}_{3 \text { phys }}$, the sum of the tendencies due to mixing, dry and wet deposition, dotted lines) processes for each of the cases.

The control run for each case is shown in black. The control run using a more basic chemical scheme (which the case 1,2 and 5 sensitivity tests are based on) is shown in purple. Changing the chemical scheme does not affect the broad features in the processing, except in case 3 , where the trajectories pass over Nova Scotia. In the basic chemistry run, dry deposition over the land removes $\mathrm{O}_{3}$ in the boundary layer, causing the decrease in $\Delta \mathrm{O}_{3 \text { phys }}$ on days 205 to 206 (Fig. 9c). The inclusion of the more complex isoprene mechanism in the control run produces more $\mathrm{O}_{3}$ in the boundary layer when the trajectories encounter isoprene emissions from Nova Scotia, which replenishes some of the $\mathrm{O}_{3}$ lost by dry deposition. This change to the chemical scheme changes the background mixing ratios and the vertical gradient in

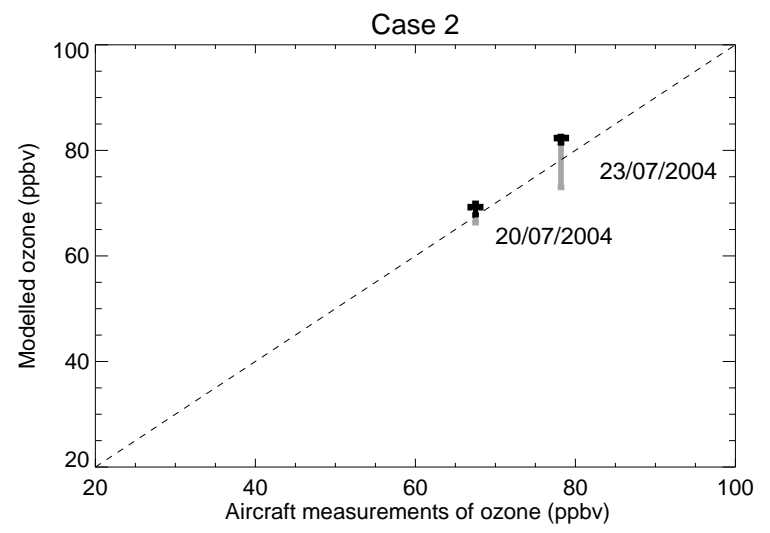

(b) Case 2

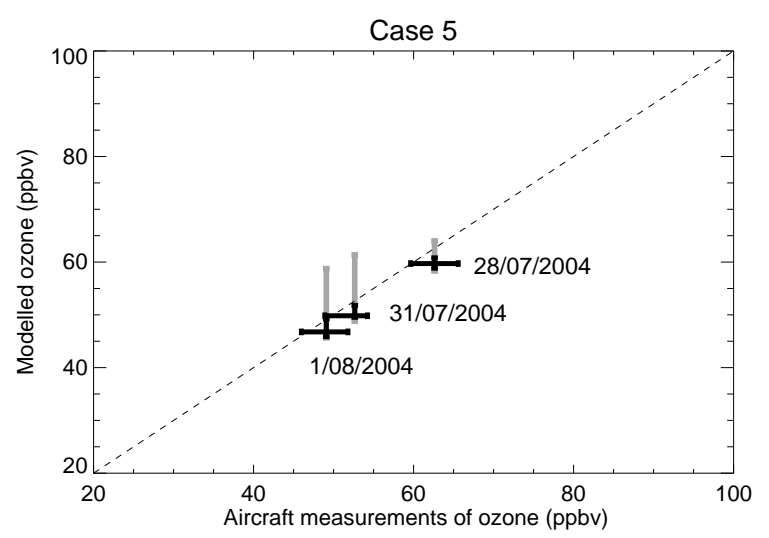

(d) Case 5

the boundary layer, which affects $\Delta \mathrm{O}_{3 \text { phys }}$ along the reference trajectory through mixing. An effect of this nature will be referred to here as indirect. In this example, altering the chemical scheme has a direct effect on $\Delta \mathrm{O}_{3 \text { chem }}$ and an indirect effect on $\Delta \mathrm{O}_{3 \text { phys. }}$. Conversely, changing the physical processes acting on $\mathrm{O}_{3}$ precursors can affect the diagnosed $\Delta \mathrm{O}_{3 \text { chem }}$ indirectly.

Although there is a clear difference in the $\Delta \mathrm{O}_{3 \text { chem }}$ between the two chemical schemes (black and purple solid lines) in all cases, there is also an indirect effect on the $\Delta \mathrm{O}_{3 \text { phys }}$ (black and purple dotted lines), which opposes the difference in each case. This indirect effect, or compensation effect, is also found when changing the physical parameters. Often, the simulations that give the least net photochemical $\mathrm{O}_{3}$ production give the largest $\mathrm{O}_{3}$ increases through mixing, and vice versa.

For example, the case 3 simulation with no cloud. Removing the cloud directly increases the photochemical destruction of $\mathrm{O}_{3}$ (solid light blue line in Fig. 9c). However, there is also an indirect effect on the physical processing (dotted light 


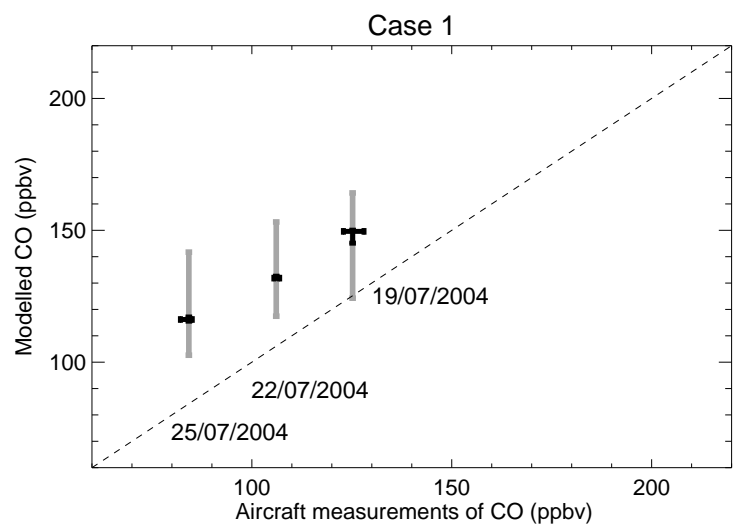

(a) Case 1

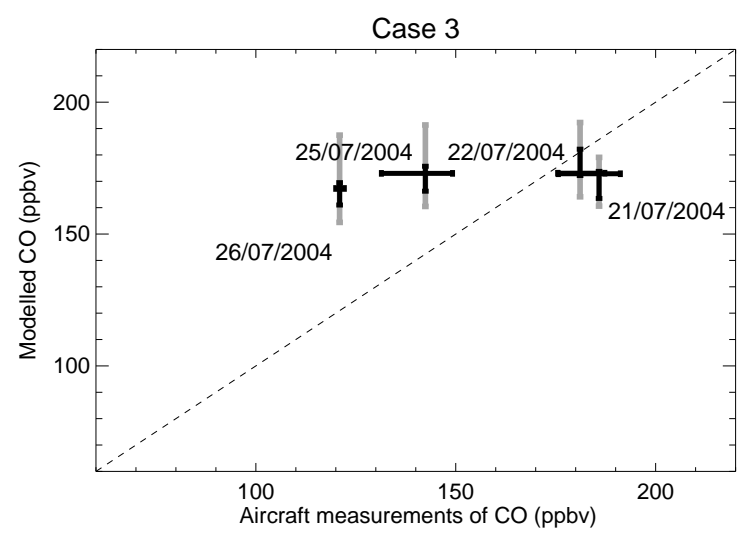

(c) Case 3

Fig. 8. Comparison of modelled and observed CO, as Fig. 6.

blue line). By changing the photochemical production and loss of $\mathrm{O}_{3}$ throughout the ensemble, the vertical profile and gradient changes, and therefore so does the mixing tendency. This opposes the decrease in $\mathrm{O}_{3}$ from chemistry, therefore the net effect is small. In contrast, halving the anthropogenic emissions (dark green) gives a similar end result, but through $\Delta \mathrm{O}_{3 \text { phys }}$ alone.

In case 2 , there is very little dilution of $\mathrm{O}_{3}$ directly, however mixing affects $\mathrm{O}_{3}$ mixing ratios indirectly through the dilution of precursors. There is $5.7 \mathrm{ppbv}$ more net photochemical $\mathrm{O}_{3}$ production in the run with weak mixing (dark blue solid) than the run with strong mixing (light blue solid), whereas the difference between the physical $\mathrm{O}_{3}$ tendencies in these two runs is only $0.6 \mathrm{ppbv}$. The physical removal of $\mathrm{O}_{3}$ precursors from the air mass has an effect on the photochemistry within that air mass, which is more important than mixing $\mathrm{O}_{3}$ itself. These examples show how the physical and chemical processes acting on an air mass are interrelated, and that it is necessary to have fully coupled mixing and photo-

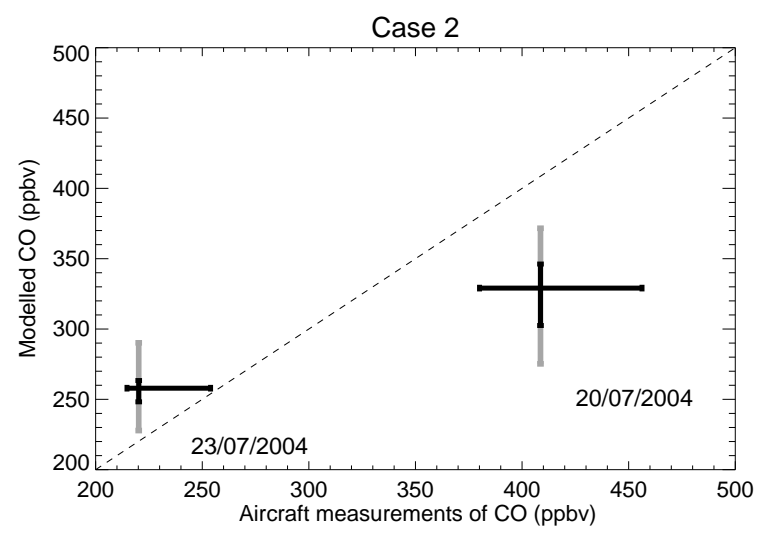

(b) Case 2

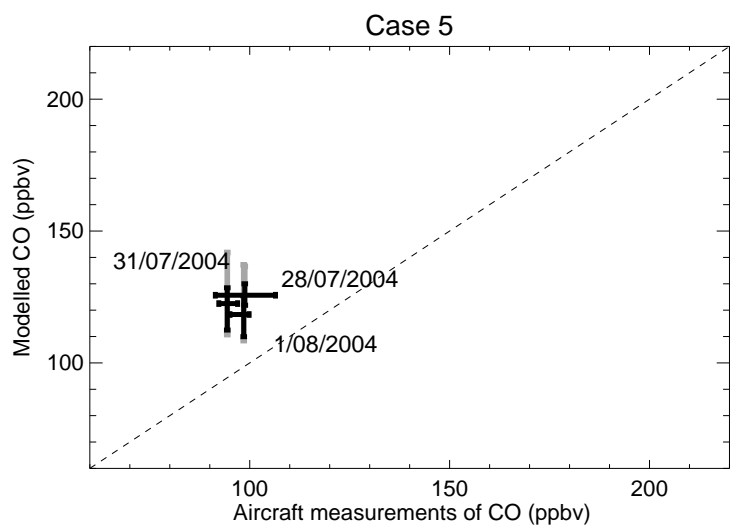

(d) Case 5

chemistry in a Lagrangian model if the processes are to be captured realistically.

Real et al. (2007) have shown that biomass burning aerosol was important photochemically for this case. They implemented a different photolysis scheme (Fast-J) into CiTTyCAT, which incorporates the effects of aerosol on photolysis rates. Averaging over the five day simulation, Real et al. (2007) found that the photolysis rate coefficient $j \mathrm{NO}_{2}$ changed by $-21 \%$ when the aerosol was included. A similar order of magnitude reduction is seen here when comparing the control run (climatological clouds) with a run with no cloud, as $j \mathrm{NO}_{2}$ changes by up to $-30 \%$ when cloud is removed. The overall effect on $\mathrm{O}_{3}$ when cloud is removed is a reduction in the net photochemical production of $\mathrm{O}_{3}$ (because light is no longer reflected off the clouds below the plume), however this is slightly offset by the indirect effect on mixing, which causes $\Delta \mathrm{O}_{3 \text { phys }}$ to change in the opposite direction compared to $\Delta \mathrm{O}_{3 \mathrm{chem}}$. This suggests that although the photolysis rates are likely to be affected by the presence of aerosol, the $\mathrm{O}_{3}$ mixing ratios may see a small difference, 


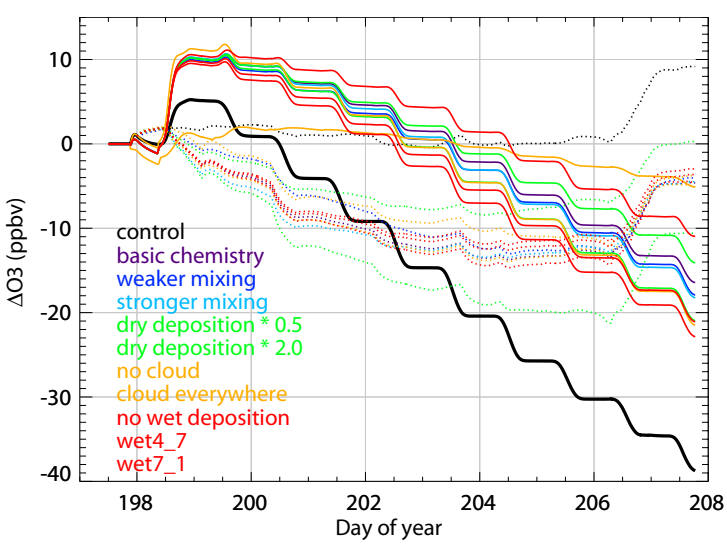

(a) Case 1

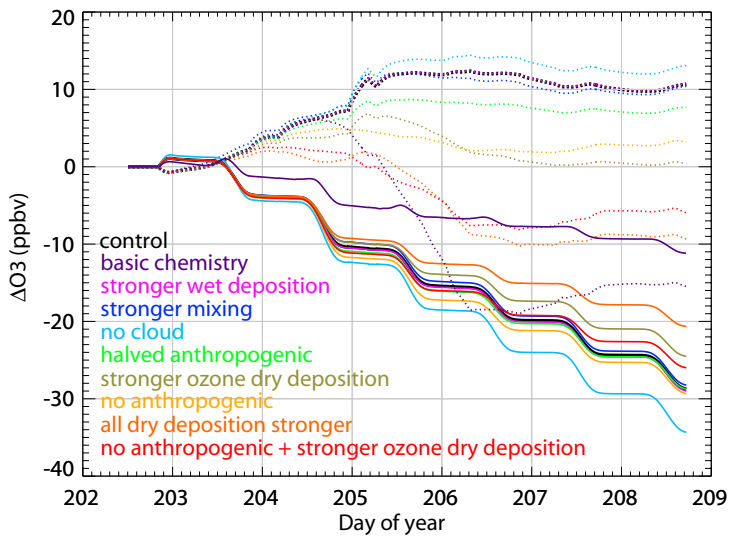

(c) Case 3

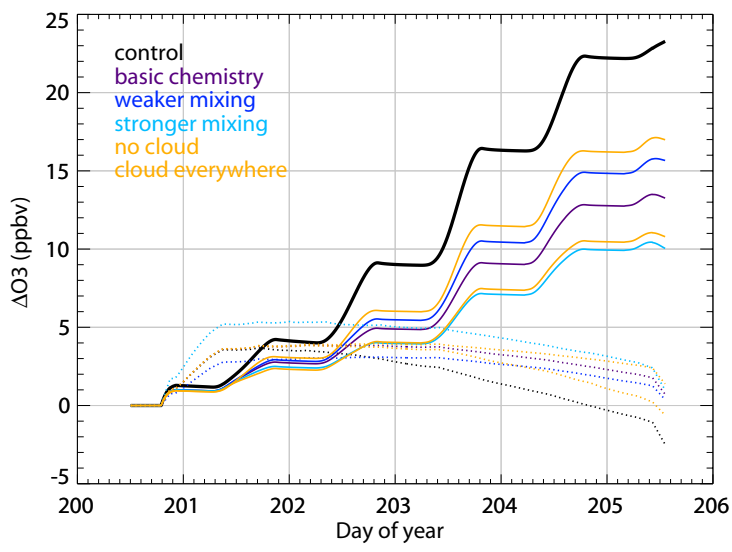

(b) Case 2

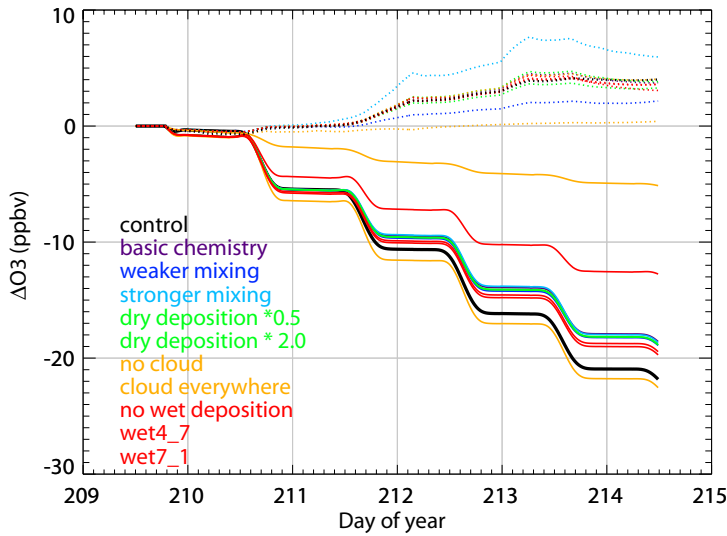

(d) Case 5

Fig. 9. $\Delta \mathrm{O}_{3}$ partitioned by process and accumulated along the reference trajectory, as Fig. 5. Solid lines are from the accumulation of tendencies from chemistry $\left(\Delta \mathrm{O}_{3 \mathrm{chem}}\right)$, and dotted lines are from the accumulation of tendencies from physical processes $\left(\Delta \mathrm{O}_{3 \text { phys }}\right)$.

as compensating effects make $\mathrm{O}_{3}$ mixing ratios relatively insensitive to small changes to the model set up.

The only case with sustained net photochemical production of $\mathrm{O}_{3}$ is the biomass burning plume, case 2. There is some net photochemical production at the start of cases 1 and 3, however after the first day there is a diurnal cycle of stronger photochemical removal in the day and weaker at night in all the low altitude cases. Even after several days of net photochemical destruction, the $\mathrm{O}_{3}$ is still elevated from background mixing ratios in cases 3 and 5 . The rate of net photochemical $\mathrm{O}_{3}$ destruction is approximately -5 ppbv per day in the control runs (black) for all the low altitude cases (consistent with the loss found by Real et al., 2008). This indicates that it is the differences in the physical processing and the interaction with the surface that is defining the differences between these cases.

\subsection{Summary of all cases}

Modelled $\Delta \mathrm{O}_{3}$, partitioned by process, from each of the simulated cases is summarised in Fig. 10, alongside the total
$\Delta \mathrm{O}_{3}$ observed by the aircraft. The first three bars for each case show the value of $\Delta \mathrm{O}_{3 \text { chem }}$ (dark blue), $\Delta \mathrm{O}_{3 \text { phys }}$ (cyan) and $\Delta \mathrm{O}_{3 \text { total }}$ (yellow) for the reference trajectory from the ensembles shown in Figs. 1, 2, 3 and 4 (these diagnostics are only saved for the reference trajectory). The error bars for each case are the minimum and maximum reference trajectory values from the sensitivity tests, plus an estimate for the ensemble spread for the $\Delta \mathrm{O}_{3 \text { total }}$ bar. There will also be an ensemble spread for $\Delta \mathrm{O}_{3 \text { chem }}$ and $\Delta \mathrm{O}_{3 \text { phys }}$, but information about this is not saved. Observed $\Delta \mathrm{O}_{3 \text { total }}$ is shown by the brown bar, and is estimated taking into account the variability in both the upstream and downstream observations.

For all cases, $\Delta \mathrm{O}_{3 \text { phys }}$ is smaller in magnitude than $\Delta \mathrm{O}_{3 \text { chem }}$, and acting in the opposite direction except for case 3 . This is not because the physical processes necessarily have a small effect, it is because the physical processes often act in opposing directions at different stages in the simulation, depending on altitude and background profile, whereas the photochemistry in these cases generally acts in one direction (positive in the forest fire case, negative in the lower tropospheric cases). 


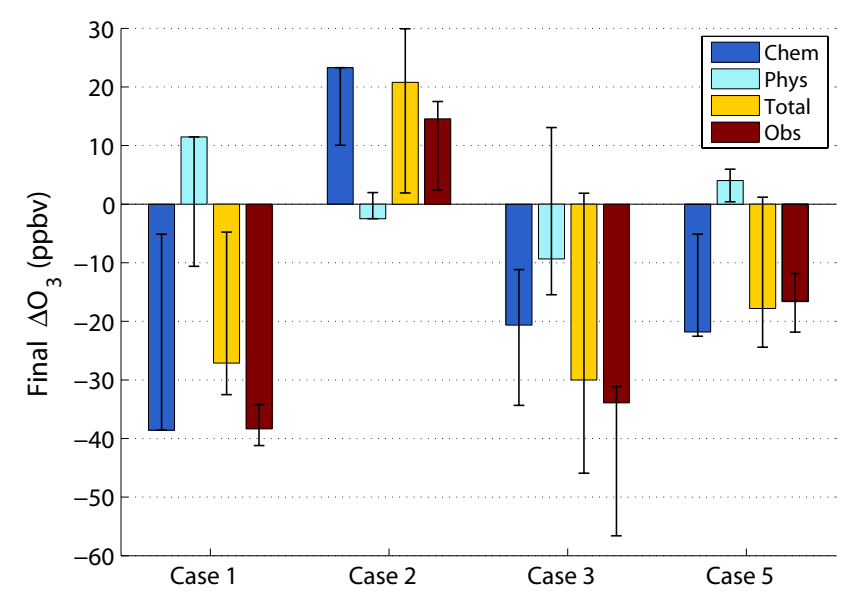

Fig. 10. $\Delta \mathrm{O}_{3}$ partitioned by process between the first and last Lagrangian match window for each case. Blue: $\Delta \mathrm{O}_{3}$ from chemical tendencies in the model. Cyan: $\Delta \mathrm{O}_{3}$ from physical process tendencies in the model. Yellow: total $\Delta \mathrm{O}_{3}$ in the model. Brown: observed $\Delta \mathrm{O}_{3}$, estimated taking into account both upstream and downstream variability. The blue, cyan and yellow bars show the best case simulation; error bars encompass the full range of the sensitivity tests, and take in to account the ensemble spread for $\Delta \mathrm{O}_{3}$.

Case 2 is the simplest scenario, as the high altitude of the air mass means that mixing is the only physical process in action. As the surrounding air contains a similar mixing ratio of $\mathrm{O}_{3}$, the mixing tendency is very small. In cases where $\mathrm{O}_{3}$ is strongly dominated by photochemistry (cases 2 and 5), the model can reproduce $\Delta \mathrm{O}_{3}$ more accurately than when physical processes are important (cases 1 and 3), suggesting that the physical processes are more difficult to model correctly.

The large range in the $\Delta \mathrm{O}_{3 \text { chem }}$ error bars is due to the differences between the two different chemical schemes (black and purple in Fig. 9). Of all the sensitivity tests, the largest change to the final $\Delta \mathrm{O}_{3}$ is caused by changing the chemical scheme in the model, however the features in $\Delta \mathrm{O}_{3 \mathrm{chem}}$ and $\Delta \mathrm{O}_{3 \text { phys }}$ are the same using both schemes $\left(\Delta \mathrm{O}_{3 \text { chem }}\right.$ is still greater than $\Delta \mathrm{O}_{3 \text { phys }}$ using the basic scheme), except for case 3 . The more extensive chemical scheme (which includes a more detailed isoprene mechanism) gives more $\mathrm{O}_{3}$ production (in the biomass burning plume) and more $\mathrm{O}_{3}$ destruction (in the lower tropospheric plumes) than the basic chemical scheme.

There is overlap between the modelled and observed $\Delta \mathrm{O}_{3 \text { total }}$, except in case 1 . However, it should be noted that the sensitivity tests for cases 1, 2 and 5 used the basic chemistry scheme. If these tests used the full chemistry scheme and the model responded similarly, the results would cluster around the control simulation with the new chemistry (the coloured bars in Fig. 10). This would make the range of the case 1 sensitivity tests overlap with the observations.

\section{Discussion and conclusions}

Four cases of long-range transport from the ITCTLagrangian 2004 experiment have been studied using a Lagrangian photochemical model. For each case, the air mass was intercepted several times by research aircraft during transport across the North Atlantic. A novel scheme for mixing through an ensemble of trajectories is used, which simulates the magnitude and variability of the observed $\mathrm{O}_{3}$, $\mathrm{CO}, \mathrm{NO}_{\mathrm{y}}$ and some hydrocarbons. The trajectory ensembles were created by releasing trajectories from points every 10s along the upstream flight track within the flight segment that matches with flights downstream. Thus each ensemble includes spread associated with sensitivity of trajectories to initial location and variability in the observed concentrations within the upstream air mass. Many ensemble simulations have been run for each case, which span the sensitivity to physical parameters. The range of parameters has been guided by the observations in the ITCT-Lagrangian 2004 campaign. Two chemical schemes of differing complexity are also used to characterise the sensitivity to the formulation of chemistry in the model. In this way, the study examines parametric and structural model uncertainty and compares it with initial condition sensitivity and observed variability. Where robust Lagrangian links have been established using coincident matches between trajectories and hydrocarbon fingerprints (Methven et al., 2006; Arnold et al., 2007), the model reproduces the average $[\mathrm{OH}]$ following each air mass inferred from hydrocarbon measurements and does not systematically under- or over-estimate $\overline{[\mathrm{OH}]}$. This indicates that this model of intermediate complexity produces realistic levels of photochemical activity, for these examples of midlatitude transport across the North Atlantic.

The net change in ozone $\left(\Delta \mathrm{O}_{3}\right)$ modelled following the centroid (reference trajectory) of the air mass is in agreement with the pseudo Lagrangian aircraft observations in all four cases, given the observed variability upstream and downstream and the uncertainty associated with model parameters. The trajectory ensemble spread in $\mathrm{O}_{3}$ for each case is similar to the spread in the reference trajectories for the model parameter sensitivity tests (not including changing the chemical scheme). This means that the uncertainty in the initial conditions and the trajectory followed is of the same magnitude as the uncertainty in defining the model parameters.

Since the simulated $\Delta \mathrm{O}_{3}$ is supported by the observations, it is reasonable to use the model to ascribe the changes in composition to different processes acting in the model, and assume that the estimates represent the relative importance of those processes in the atmosphere. Accumulating Lagrangian tendencies associated with each process separately, using Eq. (11), revealed that the magnitude of $\Delta \mathrm{O}_{3 \text { chem is greater }}$ than $\Delta \mathrm{O}_{3 \text { phys }}$ in all cases. This is in part explained by cancellation effects on the physical processing, as mixing can be a positive or a negative tendency. In contrast, each case is in 
a regime of either net photochemical production (case 2) or destruction (cases 1, 3 and 5) of $\mathrm{O}_{3}$. In the high altitude fire plume (case 2), chemical production of $\mathrm{O}_{3}$ is dominant due to the abundance of precursors and low humidity. Cases 1 and 3 are both of low altitude transport of anthropogenic pollution. Case 5 is of transport behind a cold front at slightly higher altitude $(\sim 2 \mathrm{~km})$ than cases 1 and 3 . These air masses were in an $\mathrm{O}_{3}$ photochemical loss regime overall (approximately -5 ppbv per day in all control runs), due to the high humidity and temperature at low altitudes. This suggests that the differences in the $\mathrm{O}_{3}$ evolution in each case are due to differences in the physical processing.

A clear example of the interaction between the physical and chemical processes can be seen in case 2. Altering the mixing parameter in case 2 results in a small direct change in $\Delta \mathrm{O}_{3 \text { phys }}$, as the background $\mathrm{O}_{3}$ is similar to that in the plume. However, the change to the mixing of precursors indirectly affects the photochemical production of $\mathrm{O}_{3}$, such that the change to $\Delta \mathrm{O}_{3 \text { chem }}$ is greater than the change to $\Delta \mathrm{O}_{3 \text { phys }}$. This highlights the necessity of coupling the chemistry and mixing in a Lagrangian model, as such indirect effects would not be seen if the model were not fully coupled.

In the cases where photochemistry is the dominant influence on $\mathrm{O}_{3}$ (cases 2 and 5), there is better agreement with observations compared to the lower altitude cases where physical processing is more important (cases 1 and 3, where the physical interaction with the surface is stronger). This indicates a greater uncertainty in modelling the emissions, the dry deposition and the background profile in the boundary layer than in the chemical processing.

The relatively poor quality of the Lagrangian match in case 3 , due partly to strong heterogeneity within the air mass leaving the USA (Methven et al., 2006; Real et al., 2008), means that the model results running from the measurements of the upwind aircraft are less well constrained by downwind measurements, and the inferences regarding model parameters are weaker. Increasing the dry deposition (as a simple representation of a boundary layer loss that is missing in the model) was required to bring the case 3 ensemble into agreement with the observations, as $\mathrm{O}_{3}$ was overestimated with the default dry deposition.

The sensitivity tests for the lower tropospheric cases show that changing a model parameter has a different effect dependent on the case, and will often cause compensating effects in $\Delta \mathrm{O}_{3 \text { chem }}$ and $\Delta \mathrm{O}_{3 \text { phys }}$, resulting in a small net effect. Case 3 travels at the lowest altitude, and therefore responds most strongly to changes in the emissions and the dry deposition. Case 1 is slightly higher in altitude ( $\sim 0.5$ to $1.5 \mathrm{~km}$ ) and here the dry deposition is still one of the most important factors, however wet deposition and cloud cover are also just as important. Case 5 is an air mass at $\sim 2 \mathrm{~km}$ altitude, and here the dry deposition tests make very little difference. The cloud cover is most important, followed by removing wet deposition and changing the mixing parameters (as air is mixed up from nearer the surface). This suggests that the model is only sensitive to dry deposition when the air mass of interest is below $2 \mathrm{~km}$, in these cases of transport over the North Atlantic. If the air mass is within the well-mixed boundary layer, the model is less sensitive to the mixing parameterisation than for a plume just above the boundary layer.

In a Lagrangian modelling framework, the model error is eventually dominated by the chaotic nature of the atmosphere. Not only do the members of a trajectory ensemble spread, but the neighbours of a coherent ensemble change continuously with air masses from different origins. The most important factor influencing the mixing in the model is the background profile of composition. The assumption that it evolves only in the vertical, from the air masses sampled initially, becomes a greater limitation with time. One possible approach is to use a domain filling set of trajectories so that the neighbouring composition is known, even if it originates far from the target air mass. However, this is perhaps not cost effective relative to a grid-based model and the formulation of mixing is more uncertain. Despite this, in the cases examined, the approach agrees with Lagrangian observations spaced up to ten days apart, when observed variability within air masses and uncertainty associated with model parameters are accounted for. In contrast, in global Eulerian models, the limited resolution results in a misrepresentation of the rate of mixing between locations, which can then impact radical concentrations due to nonlinearity in the chemistry (e.g. Crowther et al., 2002).

In the cases examined spanning the North Atlantic, reduced complexity in the chemical mechanism introduces a similar uncertainty to variation in the parameters of the physical processes and both are larger than the observed variability within air masses. Therefore, it is possible to anticipate systematic errors in long-term simulations by CTMs using chemical schemes of similar reduced complexity. It would be instructive to compare CTMs by sampling them along the reference trajectories of the ITCT-Lagrangian cases as one means of exploring the sensitivity of a range of models to their formulation of chemical and physical processes.

Acknowledgements. MC is grateful for a Ph.D. studentship funded by the Natural Environment Research Council of the UK. The authors wish to thank the editor, L. Ganzeveld, and three anonymous referees for their helpful comments, which have been used to improve this paper.

Edited by: L. Ganzeveld

\section{References}

Arnold, S. R., Chipperfield, M. P., Blitz, M. A., Heard, D. E., and Pilling, M. J.: Photodissociation of acetone: Atmospheric implications of temperature-dependent quantum yields, Geophys. Res. Lett., 31, L07110, doi:10.1029/2003GL019099, 2004.

Arnold, S. R., Methven, J., Evans, M. J., Chipperfield, M. P., Lewis, A. C., Hopkins, J. R., McQuaid, J. B., Watson, N., Purvis, R. M., 
Lee, J. D., Atlas, E. L., Blake, D. R., and Rappengluck, B.: Statistical inference of $\mathrm{OH}$ concentrations and air mass dilution rates from successive observations of nonmethane hydrocarbons in single air masses, J. Geophys. Res., 112, D10S40, doi:10.1029/2006JD007594, 2007.

Beljaars, A.: Parameterisation of physical processes: Turbulence and mixing, in: Encyclopaedia of Atmospheric Sciences, edited by: Holton, J., Pyle, J., and Curry, J., Academic Press, 1705$1717,2002$.

Bethan, S., Vaughan, G., Gerbig, C., Volz-Thomas, A., Richer, H., and Tiddeman, D. A.: Chemical air mass differences near fronts, J. Geophys. Res., 103, 13413-13434, doi:10.1029/98JD00535, 1998.

Collins, W. J., Stevenson, D. S., Johnson, C. E., and Derwent, R. G.: Tropospheric ozone in a global-scale three-dimensional Lagrangian model and its response to $\mathrm{NO}_{\mathrm{x}}$ emission controls, J. Atmos. Chem., 26, 223-274, doi:10.1023/A:1005836531979, 1997

Collins, W. J., Stevenson, D. S., Johnson, C. E., and Derwent, R. G.: The European regional ozone distribution and its links with the global scale for the years 1992 and 2015, Atmos. Environ., 34, 255-267, doi:10.1016/S1352-2310(99)00226-5, 2000.

Cooper, O., Moody, J., Parrish, D., Trainer, M., Ryerson, T., Holloway, J., Hübler, G., Fehsenfeld, F., and Evans, M.: Trace gas composition of midlatitude cyclones over the western North Atlantic Ocean: A conceptual model, J. Geophys. Res., 107, 4057, doi:10.1029/2001JD000902, 2002.

Crowther, R., Law, K., Pyle, J., Bekki, S., and Smit, H.: Characterising the effect of large-scale model resolution upon calculated $\mathrm{OH}$ production using MOZAIC data, Geophys. Res. Lett., 29, 1613, doi:10.1029/2002GL014660, 2002.

Derwent, R., Stevenson, D., Doherty, R., Collins, W., and Sanderson, M.: How is surface ozone in Europe linked to Asian and North American NOx emissions?, Atmos. Environ., 42, 74127422, doi:10.1016/j.atmosenv.2008.06.037, 2008.

Derwent, R. G. and Jenkin, M. E.: Hydrocarbons and the long-range transport of ozone and PAN across Europe, Atmos. Environ., 25A, 1661-1678, 1991.

Evans, M. J.: Lagrangian modelling of tropospheric field measurements, Ph.D. thesis, University of Cambridge, 1999.

Evans, M. J., Shalcross, D. E., Law, K. S., Wild, J. O. F., Simmonds, P. G., Spain, T. G., Berrisford, P., Methven, J., Lewis, A. C., McQuaid, J. B., Pilling, M. J., Bandy, B. J., Penkett, S. A., and Pyle, J. A.: Evaluation of a Lagrangian box model using field measurements from EASE (Eastern Atlantic Summer Experiment) 1996, Atmos. Environ., 34, 3843-3863, 2000.

Fairall, C. W., Bariteau, L., Grachev, A. A., Hill, R. J., Wolfe, D. E., Brewer, W. A., Tucker, S. C., Hare, J. E., and Angevine, W. M.: Turbulent bulk transfer coefficients and ozone deposition velocity in the International Consortium for Atmospheric Research into Transport and Transformation, J. Geophys. Res., 111, D23S20, doi:10.1029/2006JD007597, 2006.

Fehsenfeld, F. C., Ancellet, G., Bates, T. S., Goldstein, A. H., Hardesty, R. M., Honrath, R., Law, K. S., Lewis, A. C., Leaitch, R., Mckeen, S., Meagher, J., Parrish, D. D., Pszenny, A. A. P., Russell, P. B., Schlager, H., Seinfeld, J., Talbot, R., and Zbinden, R.: International Consortium for Atmospheric Research on Transport and Transformation (ICARTT): North America to EuropeOverview of the 2004 summer field study, J. Geophys. Res., 111,
D23S01, doi:10.1029/2006JD007829, 2006.

Fiore, A. M., Dentener, F. J., Wild, O., Cuvelier, C., Schultz, M. G., Hess, P., Textor, C., Schulz, M., Doherty, R. M., Horowitz, L. W., MacKenzie, I. a., Sanderson, M. G., Shindell, D. T., Stevenson, D. S., Szopa, S., Van Dingenen, R., Zeng, G., Atherton, C., Bergmann, D., Bey, I., Carmichael, G., Collins, W. J., Duncan, B. N., Faluvegi, G., Folberth, G., Gauss, M., Gong, S., Hauglustaine, D., Holloway, T., Isaksen, I. S. a., Jacob, D. J., Jonson, J. E., Kaminski, J. W., Keating, T. J., Lupu, A., Marmer, E., Montanaro, V., Park, R. J., Pitari, G., Pringle, K. J., Pyle, J. A., Schroeder, S., Vivanco, M. G., Wind, P., Wojcik, G., Wu, S., and Zuber, A.: Multimodel estimates of intercontinental sourcereceptor relationships for ozone pollution, J. Geophys. Res., 114, 1-21, doi:10.1029/2008JD010816, 2009.

Guenther, A., Karl, T., Harley, P., Wiedinmyer, C., Palmer, P. I., and Geron, C.: Estimates of global terrestrial isoprene emissions using MEGAN (Model of Emissions of Gases and Aerosols from Nature), Atmos. Chem. Phys., 6, 3181-3210, doi:10.5194/acp-63181-2006, 2006.

Haynes, P. and Anglade, J.: The vertical-scale cascade in atmospheric tracers due to large-scale differential advection, J. Atmos. Sci., 54, 1121-1136, 1997.

Holtslag, A.: Boundary Layers: Modelling and Parameterisation, in: Encyclopaedia of Atmospheric Sciences, edited by: Holton, J., Pyle, J., and Curry, J., Academic Press, 253-261, 2002.

Horowitz, L. W., Fiore, A. M., Milly, G. P., Cohen, R. C., Perring, A., Wooldridge, P. J., Hess, P. G., Emmons, L. K., and Lamarque, J.-F.: Observational constraints on the chemistry of isoprene nitrates over the eastern United States, J. Geophys. Res., 112, D12S08, doi:10.1029/2006JD007747, 2007.

Hough, A. M.: The calculation of photolysis rates for use in global tropospheric modelling studies, AERE Report R-13259, 1988.

Hough, A. M.: Development of a two-dimensional global tropospheric model: model chemistry, J. Geophys. Res., 96, 73257362, 1991.

IUPAC: Evaluated kinetic data, http://www.iupac-kinetic.ch.cam. ac.uk/, last access: 23 January 2008.

Jacob, D. J., Crawford, J. H., Kleb, M. M., Connors, V. S., Bendura, R. J., Raper, J. L., Sachse, G. W., Gille, J. C., Emmons, L., and Heald, C. L.: Transport and Chemical Evolution over the Pacific (TRACE-P) aircraft mission: Design, execution, and first results, J. Geophys. Res., 108, 9000, doi:10.1029/2002JD003276, 2003.

Jenkin, M., Saunders, S., and Pilling, M.: The tropospheric degradation of volatile organic compounds: A protocol for mechanism development, Atmos. Environ., 31, 81-104, 1997.

Karl, T., Potosnak, M., Guenther, A., Clark, D., Walker, J., Herrick, J., and Geron, C.: Exchange processes of volatile organic compounds above a tropical rain forest: Implications for modeling tropospheric chemistry above dense vegetation, J. Geophys. Res., 109, D18306, doi:10.1029/2004JD004738, 2004.

Lee, S.-H., Kim, S.-W., Trainer, M., Frost, G. J., McKeen, S. A., Cooper, O. R., Flocke, F., Holloway, J. S., Neuman, J. A., Ryerson, T., Senff, C. J., Swanson, A. L., and Thompson, A. M.: Modeling ozone plumes observed downwind of New York City over the North Atlantic Ocean during the ICARTT field campaign, Atmos. Chem. Phys., 11, 7375-7397, doi:10.5194/acp-11-73752011, 2011.

Lewis, A. C., Evans, M. J., Methven, J., Watson, N., Lee, J. D., Hopkins, J. R., Purvis, R. M., Arnold, S. R., McQuaid, J. B., Whalley, 
L. K., Pilling, M. J., Heard, D. E., Monks, P. S., Parker, A. E., Reeves, C. E., Oram, D. E., Mills, Gand Bandy, B. J., Stewart, D., Coe, H., Williams, P., and Crosier, J.: Chemical composition observed over the mid-Atlantic and the detection of pollution signatures far from source regions, J. Geophys. Res., 112, D10S39, doi:10.1029/2006JD007584, 2007.

Li, Q.: Transatlantic transport of pollution and its effects on surface ozone in Europe and North America, J. Geophys. Res., 107, 4166, doi:10.1029/2001JD001422, 2002.

McKenna, D.: Analytic solutions of reaction diffusion equations and implications for the concept of an air parcel, J. Geophys. Res., 102, 13719-13725, 1997.

Methven, J.: Offline trajectories: Calculation and accuracy, Tech. Rep., u. K. Univ. Global Atmos. Modell. Program, Dep. of Meteorol., Univ. of Reading, Reading, U. K., 1997.

Methven, J., Arnold, S. R., O’Connor, F. M., Barjat, H., Dewey, K., Kent, J., and Brough, N.: Estimating photochemically produced ozone throughout a domain using flight data and a Lagrangian model, J. Geophys. Res., 108, 4271, doi:10.1029/2002JD002955, 2003.

Methven, J., Arnold, S. R., Stohl, A., Evans, M. J., Avery, M., Law, K., Lewis, A. C., Monks, P. S., Parrish, D. D., Reeves, C. E., Schlager, H., Atlas, E., Blake, D. R., Coe, H., Crosier, J., Flocke, F. M., Holloway, J. S., Hopkins, J. R., McQuaid, J., Purvis, R., Rappengluck, B., Singh, H. B., Watson, N. M., Whalley, L. K., and Williams, P. I.: Establishing Lagrangian connections between observations within air masses crossing the Atlantic during the ICARTT experiment, J. Geophys. Res., 111, D23S62, doi:10.1029/2006JD007540, 2006.

Neuman, J. A., Parrish, D. D., Trainer, M., Ryerson, T. B., Holloway, J. S., Nowak, J. B., Swanson, A., Flocke, F., Roberts, J. M., Brown, S. S., Stark, H., Sommariva, R., Stohl, A., Peltier, R., Weber, R., Wollny, A. G., Sueper, D. T., Hubler, G., and Fehsenfeld, F. C.: Reactive nitrogen transport and photochemistry in urban plumes over the North Atlantic, J. Geophys. Res., 111, D23S54, doi:10.1029/2005JD007010, 2006.

O’Brien, L. M., Harris, N. R. P., Robinson, A. D., Gostlow, B., Warwick, N., Yang, X., and Pyle, J. A.: Bromocarbons in the tropical marine boundary layer at the Cape Verde Observatory - measurements and modelling, Atmos. Chem. Phys., 9, 9083-9099, doi:10.5194/acp-9-9083-2009, 2009.

Olivier, J., Van Aardenne, J., Dentener, F., Pagliari, V., Ganzeveld, L., and Peters, J.: Recent trends in global greenhouse gas emissions: regional trends 1970-2000 and spatial distribution of key sources in 2000, Environ. Sci., 2, 81-99, doi:10.1080/15693430500400345, 2005.

Owen, R. C., Cooper, O. R., Stohl, A., and Honrath, R. E.: An analysis of the mechanisms of North American pollutant transport to the central North Atlantic lower free troposphere, J. Geophys. Res., 111, D23S58, doi:10.1029/2006JD007062, 2006.

Penner, J. E., Atherton, C. S., Dignon, J., Ghan, S. J., Walton, J. J., and Hameed, S.: Tropospheric Nitrogen: A Three-Dimensional Study of Sources, Distributions, and Deposition, J. Geophys. Res., 96, 959-990, doi:10.1029/90JD02228, 1991.

Pisso, I., Real, E., Law, K. S., Legras, B., Bousserez, N., Attie, J. L., and Schlager, H.: Estimation of mixing in the troposphere from Lagrangian trace gas reconstructions during long-range pollution transport, J. Geophys. Res., 114, D19301, doi:10.1029/2008JD011289, 2009.
Pugh, T. A. M., MacKenzie, A. R., Hewitt, C. N., Langford, B., Edwards, P. M., Furneaux, K. L., Heard, D. E., Hopkins, J. R., Jones, C. E., Karunaharan, A., Lee, J., Mills, G., Misztal, P., Moller, S., Monks, P. S., and Whalley, L. K.: Simulating atmospheric composition over a South-East Asian tropical rainforest: performance of a chemistry box model, Atmos. Chem. Phys., 10, 279-298, doi:10.5194/acp-10-279-2010, 2010.

Pugh, T. A. M., Cain, M., Methven, J., Wild, O., Arnold, S. R., Real, E., Law, K. S., Emmerson, K. M., Owen, S. M., Pyle, J. A., Hewitt, C. N., and MacKenzie, A. R.: A Lagrangian model of air-mass photochemistry and mixing using a trajectory ensemble: the Cambridge Tropospheric Trajectory model of Chemistry And Transport (CiTTyCAT) version 4.2, Geosci. Model Dev., 5, 193 221, doi:10.5194/gmd-5-193-2012, 2012.

Read, K. A., Mahajan, A. S., Carpenter, L. J., Evans, M. J., Faria, B. V. E., Heard, D. E., Hopkins, J. R., Lee, J. D., Moller, S. J., Lewis, A. C., Mendes, L., McQuaid, J. B., Oetjen, H., Saiz-Lopez, A., Pilling, M. J., and Plane, J. M. C.: Extensive halogen-mediated ozone destruction over the tropical Atlantic Ocean, Nature, 453, 1232-1235, doi:10.1038/nature07035, 2008.

Real, E., Law, K., Wienzier, B., Fiebig, M., Petzold, A., Wild, O., Methven, J., Arnold, S., Stohl, A., Huntreiser, H., Roiger, A., Schlager, H., Stewart, D., Avery, M., Sachse, G., Browell, E., Ferrare, R., and Blake, D.: Processes influencing ozone levels in Alaskan forest fire plumes during long range transport over the North Atlantic, J. Geophys. Res., 112, D10S41, doi:10.1029/2006JD007576, 2007.

Real, E., Law, K. S., Schlager, H., Roiger, A., Huntrieser, H., Methven, J., Cain, M., Holloway, J., Neuman, J. A., Ryerson, T., Flocke, F., de Gouw, J., Atlas, E., Donnelly, S., and Parrish, D.: Lagrangian analysis of low altitude anthropogenic plume processing across the North Atlantic, Atmos. Chem. Phys., 8, 77377754, doi:10.5194/acp-8-7737-2008, 2008.

Real, E., Pisso, I., Law, K. S., Legras, B., Bousserez, N., Schlager, H., Roiger, a., and Attié, J. L.: Toward a novel high-resolution modeling approach for the study of chemical evolution of pollutant plumes during long-range transport, J. Geophys. Res., 115, 1-14, doi:10.1029/2009JD011707, 2010.

Riddle, E. E., Voss, P. B., Stohl, A., Holcomb, D., Maczka, D., Washburn, K., and Talbot, R. W.: Trajectory model validation using newly developed altitude-controlled balloons during the International Consortium for Atmospheric Research on Transport and Transformations 2004 campaign, J. Geophys. Res., 111, D23S57, doi:10.1029/2006JD007456, 2006.

Ridley, D. A. and Arnold, S. R.: Quantifying the impact of model uncertainties on chemical budgets in trans-Atlantic pollution transport, AGU Fall Meeting Abstracts, p. C191+, 2009.

Sander, S. P., Friedl, R. R., Golden, D. M., Kurylo, M. J., Moortgat, G. K., Keller-Rudek, H., Wine, P. H., Ravishankara, A. R., Kolb, C. E., Molina, M. J., Finlayson-Pitts, B. J., Huie, R. E., and Orkin, V. L.: Chemical Kinetics and Photochemical Data for Use in Atmospheric Studies, JPL Publication 06-2 Evaluation Number 15, JPL, 2006.

Saunders, S. M., Jenkin, M. E., Derwent, R. G., and Pilling, M. J.: Protocol for the development of the Master Chemical Mechanism, MCM v3 (Part A): tropospheric degradation of nonaromatic volatile organic compounds, Atmos. Chem. Phys., 3, 161-180, doi:10.5194/acp-3-161-2003, 2003. 
Singh, H., Tabazadeh, A., Evans, M., Field, B., Jacob, D., Sachse, G., Crawford, J., Shetter, R., and Brune, W.: Oxygenated volatile organic chemicals in the oceans: Inferences and implications based on atmospheric observations and air-sea exchange models, Geophys. Res. Lett., 30, 1862, doi:10.1029/2003GL017933, 2003.

Stevenson, D. S., Collins, W. J., Johnson, C. E., and Derwent, R.: Intercomparison and evaluation of atmospheric transport in a Lagrangian model (STOCHEM), and an Eulerian model (UM), using 222Rn as a short-lived tracer, Q. J. Roy. Meteorol. Soc., 124, 2477-2491, 1998.

Stohl, A., Cooper, O. R., Damoah, R., Fehsenfeld, F. C., Forster, C., Hsie, E.-Y., Hübler, G., Parrish, D. D., and Trainer, M.: Forecasting for a Lagrangian aircraft campaign, Atmos. Chem. Phys., 4, 1113-1124, doi:10.5194/acp-4-1113-2004, 2004.

Taraborrelli, D., Lawrence, M. G., Butler, T. M., Sander, R., and Lelieveld, J.: Mainz Isoprene Mechanism 2 (MIM2): an isoprene oxidation mechanism for regional and global atmospheric modelling, Atmos. Chem. Phys., 9, 2751-2777, doi:10.5194/acp-92751-2009, 2009.

Troen, I. and Mahrt, L.: A simple model of the atmospheric boundary layer: Sensitivity to surface evaporation, Bound. Lay. Meteorol., 37, 129-148, 1986.
Wild, O.: Some problems in the numerical modelling of atmospheric chemistry, Ph.D. thesis, University of Cambridge, 1995.

Wild, O. and Akimoto, H.: Intercontinental transport of ozone and its precursors in a three-dimensional global CTM, J. Geophys. Res., 106, 27729-27744, doi:10.1029/2000JD000123, 2001.

Wild, O., Law, K. S., McKenna, D. S., Bandy, B. J., Penkett, S. A., and Pyle, J. A.: Photochemical trajectory modelling studies of the North Atlantic region during August 1993, J. Geophys. Res., 101, 29269-29288, 1996.

Wild, O., Zhu, X., and Prather, M.: Fast-J: Accurate simulation of in-and below-cloud photolysis in tropospheric chemical models, J. Atmos. Chem., 37, 245-282, 2000.

Wild, O., Sundet, J. K., Prather, M. J., Isaksen, I. S. A., Akimoto, H., Browell, E. V., and Oltmans, S. J.: Chemical transport model ozone simulations for spring 2001 over the western Pacific: Comparisons with TRACE-P lidar, ozonesondes, and Total Ozone Mapping Spectrometer columns, J. Geophys. Res., 108, 8826, doi:10.1029/2002JD003283, 2003. 